Utah State University

DigitalCommons@USU

$5-28-2013$

\title{
The Economics of Fuel Management: Wildfire, Invasive Plants, and the Dynamics of Sagebrush Rangelands in the Western United States
}

\author{
Michael H. Taylor \\ University of Nevada, Reno \\ Kimberly Rollins \\ University of Nevada, Reno \\ Mimako Kobayashi \\ University of Nevada, Reno \\ Robin J. Tausch \\ USDA Forest Service
}

Follow this and additional works at: https://digitalcommons.usu.edu/sagestep_articles

Part of the Plant Sciences Commons

\section{Recommended Citation}

Taylor, M.H., K. Rollins, M. Kobayashi, and R. Tausch. 2013. The economics of fuel management: Wildfire, invasive plants, and the dynamics of sagebrush rangelands in the western United States. Journal of Environmental Management, 126: 157-173.

This Article is brought to you for free and open access by the Publications at DigitalCommons@USU. It has been accepted for inclusion in Articles by an authorized administrator of DigitalCommons@USU. For more information, please contact digitalcommons@usu.edu.

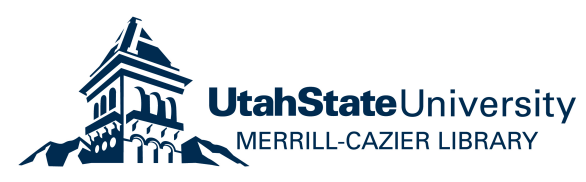




\title{
The economics of fuel management: Wildfire, invasive plants, and the dynamics of sagebrush rangelands in the western United States
}

\author{
Michael H. Taylor ${ }^{\mathrm{a}, *}$, Kimberly Rollins ${ }^{\mathrm{a}}$, Mimako Kobayashi ${ }^{\mathrm{a}, 1}$, Robin J. Tausch ${ }^{\mathrm{b}}$ \\ ${ }^{a}$ Department of Economics, University of Nevada, Reno, 1664 N. Virginia St., Reno, NV 89557, USA \\ ${ }^{\mathrm{b}}$ USDA Forest Service, Rocky Mountain Research Station - Reno, NV 920 Valley Road, Reno, NV 89512, USA
}

\section{A R T I C L E I N F O}

\section{Article history:}

Received 19 April 2012

Received in revised form

14 March 2013

Accepted 26 March 2013

Available online 28 May 2013

\section{Keywords:}

Fuel Treatment

Wildfire

Sagebrush ecosystem

Great Basin

State-and-transition model

Ecological thresholds

\begin{abstract}
A B S T R A C T
In this article we develop a simulation model to evaluate the economic efficiency of fuel treatments and apply it to two sagebrush ecosystems in the Great Basin of the western United States: the Wyoming Sagebrush Steppe and Mountain Big Sagebrush ecosystems. These ecosystems face the two most prominent concerns in sagebrush ecosystems relative to wildfire: annual grass invasion and native conifer expansion. Our model simulates long-run wildfire suppression costs with and without fuel treatments explicitly incorporating ecological dynamics, stochastic wildfire, uncertain fuel treatment success, and ecological thresholds. Our results indicate that, on the basis of wildfire suppression costs savings, fuel treatment is economically efficient only when the two ecosystems are in relatively good ecological health. We also investigate how shorter wildfire-return intervals, improved treatment success rates, and uncertainty about the location of thresholds between ecological states influence the economic efficiency of fuel treatments.
\end{abstract}

(c) 2013 Elsevier Ltd. All rights reserved.

\section{Introduction}

Wildfire suppression costs in the United States have increased steadily over the last decades (Calkin et al., 2005; GAO, 2007; Gebert et al., 2007; Stephens and Ruth, 2005; Westerling et al., 2006), with related annual expenditures by the U.S. Forest Service (USFS) and Bureau of Land Management (BLM) exceeding a billion dollars in four out of the seven years leading up to 2006 (Gebert et al., 2008). This steady increase in wildfire suppression costs is believed to be due in part to a century of U.S. federal wildfire policy that has emphasized wildfire suppression and post-fire vegetation rehabilitation over pre-fire fuel management treatments (Busenberg, 2004; Donovan and Brown, 2007; Egan, 2009; GAO, 2007; Pyne, 1982; Reinhardt et al., 2008; Stephens and Ruth, 2005). Additionally, invasive plants have been identified as contributing to increased wildfire activity on rangelands in the western United States (McIver et al 2010; Balch et al 2013). Pre-fire fuel management treatment

Abbreviations: WSS, Wyoming Sagebrush Steppe; MBS, Mountain Big Sagebrush; STM, State-and-Transition Model; NFDRS, National Fire Danger Rating System; USFS, U.S. Forest Service; BLM, Bureau of Land Management.

* Corresponding author. Tel.: +1 775784 1679; fax: +1 7757844728.

E-mail addresses: mhtaylor@unr.edu (M.H. Taylor), krollins@unr.edu (K. Rollins), mkobayashi@worldbank.org (M. Kobayashi), rtausch@fs.fed.us (R.J. Tausch).

1 Present address: Mimako Kobayashi, Agriculture and Environmental Services (AES), The World Bank, 1818 H St., NW Washington, DC 20433, USA. (henceforth fuel treatment) is recognized as an important tool to reduce the frequency of severe wildfires, and thus the expected costs of damages and wildfire suppression, and to maintain ecosystem health (GAO, 2007; Mercer et al., 2007; Reinhardt et al., 2008). Public agency efforts and expenditures, however, continue to emphasize wildfire suppression and post-fire rehabilitation over pre-fire fuel treatment. The continued focus on wildfire suppression and rehabilitation may be partly explained by the lack of empirical work establishing the economic efficiency of pre-fire fuel treatments (Gebert et al., 2008; Hesseln, 2000).

In this article we develop a simulation model to evaluate the economic efficiency of fuel treatments and apply it to two sagebrush rangeland ecosystems in the Great Basin of the western United States. Our model simulates long-run wildfire suppression costs with and without fuel treatment and takes into account the factors identified in Kline (2004) as necessary for evaluating the economic efficiency of fuel treatments. In particular, our model accounts for (i) the cumulative cost of fuel treatments over time, (ii) the likelihood of wildfire events with and without treatments, (iii) the costs of wildfire suppression and post-fire restoration, and (iv) the combined influence of wildfires and management actions on ecological conditions and ecological services over time. In accounting for all of these factors in a unified framework, this article presents an analytical tool that can be applied to evaluating the economic efficiency of fuel treatment in other ecological settings. 
To our knowledge, this article provides the first estimates of the economic efficiency of fuel treatment for rangeland ecosystems and, in particular, rangelands that have been affected by invasive plants. Rangelands are the dominant land type globally, covering $40 \%$ of total land area (Millennium Ecosystem Assessment 2005), and in the United States, covering $34.2 \%$ of total U.S. land area (Loomis, 2002). Excessively intense and/or frequent wildfires have been identified as a significant contributor to the continued ecological degradation of rangelands throughout the world, where conservative estimates are that between 10 and 20\% of global rangelands are degraded (Millennium Ecosystem Assessment 2005). Previous work has evaluated the effectiveness of fuel treatment based on biophysical outcomes without attempting to monetize the benefits (Butry, 2009; Hartsough et al., 2008), or has focused on other ecosystems (Loomis et al., 2002; Mercer et al., 2007). In a recent article, Prestemon et al. (2012) provide ranges for the expected economic benefits of mechanical fuel treatments that include wildfire suppression cost savings, but focus on nonreserved timberlands in the contiguous western United States, rather than on rangelands. Epanchin-Niell et al. (2009) develop a simulation model to analyze the economic benefits of post-fire rehabilitation for sagebrush rangeland ecosystems in the western United States. While similar in geographic scope and specification to our work, Epanchin-Niell et al. (2009) focus on post-fire rehabilitation treatment rather than preemptive fuel treatment.

We analyze the economic efficiency of fuel treatment for Wyoming Sagebrush Steppe (WSS) and Mountain Big Sagebrush (MBS) ecosystems in the Great Basin.,3 Fig. 1 depicts the geographic extent of WSS and MBS systems in the Great Basin. We focus on these ecosystems because they face the two most prominent resource management concerns in sagebrush ecosystems relative to wildfire: The expansion of native conifers such as juniper and pinyon pine (Juniperus occidentalis, Juniperus osteosperma; Pinus monophylla, Pinus edulis) in MBS systems, and the spread of exotic annual grasses such as cheatgrass (Bromus tectorum) in both systems. Native confiner expansion (henceforth pinyon-juniper expansion) from their historic ranges in upland areas into lowerelevation MBS plant communities has led to an increase in the accumulation of woody fuels and has shifted fire regimes in MBS systems from relatively frequent (10-50 years mean fire return interval), low severity wildfires to less frequent ( $>50$ years mean fire return interval), high severity wildfires (Miller and Rose, 1999; Miller and Tausch, 2001; Miller and Heyerdahl, 2008). On the other hand, annual grass invasion at the expense of native perennial species has led to increased wildfire frequency on invaded rangelands (mean fire return intervals reduced from $>50$ years to $<10$ years), and, because invasive annuals are often the first species to reemerge post-fire, an escalating cycle of increasingly frequent wildfires (Miller and Tausch, 2001; Whisenant, 1990). ${ }^{4}$

\footnotetext{
2 The Great Basin is the high desert region between the Rocky Mountain and Sierra Nevada Mountains, comprising most of Nevada and parts of Utah, California, Idaho, and Oregon.

3 WSS systems are generally found at elevations of roughly between 4700 and 6500 feet above sea level and comprise roughly 37.8 million acres in the Great Basin (26\% of the 145 million acre Great Basin). MBS systems are generally found at elevations of over 6500 feet and comprise 9.1 million acres in the Great Basin $(6.3 \%$ of total area in the Great Basin). Acreages were calculated using Great Basin Restoration Initiative data (sagemap.wr.usgs.gov; USGS, 2011).

4 More generally, pinyon-juniper expansion and annual grass invasion have been identified as major contributors to the decline of sagebrush ecosystems in the Great Basin (Miller and Tausch, 2001; Pellant, 1994), causing these ecosystems to be considered among the most endangered in the North America (Bunting et al., 2002; Noss et al., 1995). Moreover, without effective management, pinyon-juniper expansion and annual grass invasion is expected to continue in sagebrush ecosystems (Miller et al., 2000; Wisdom et al., 2002).
}

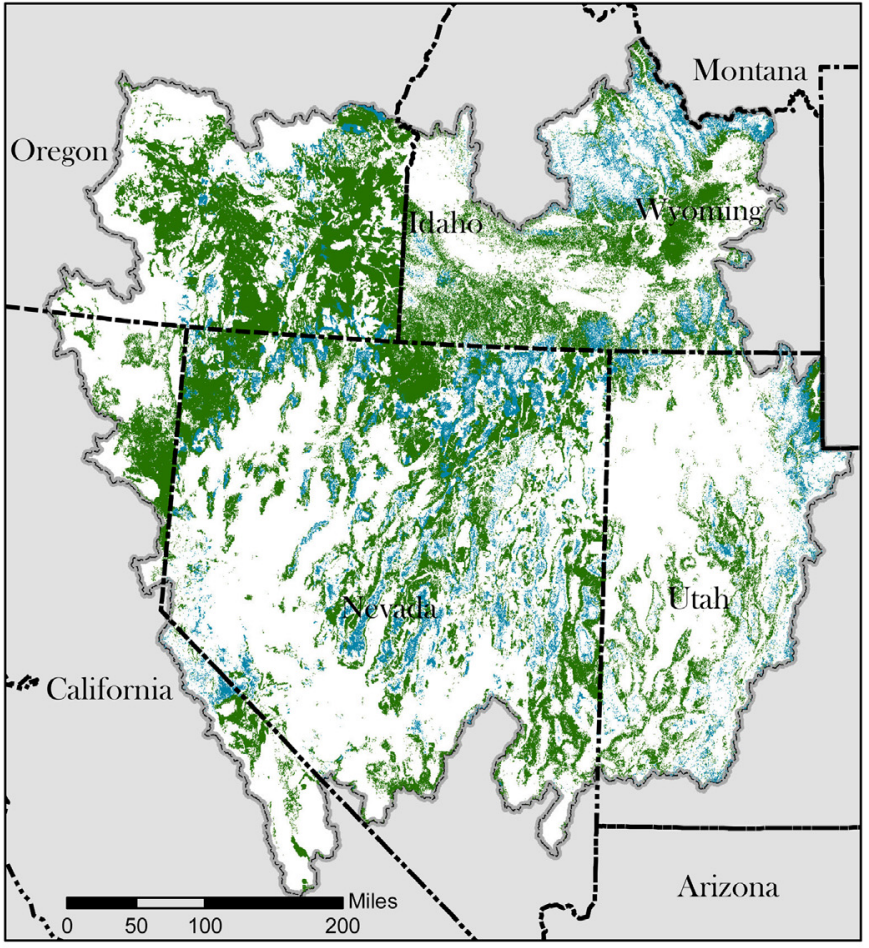

Legend

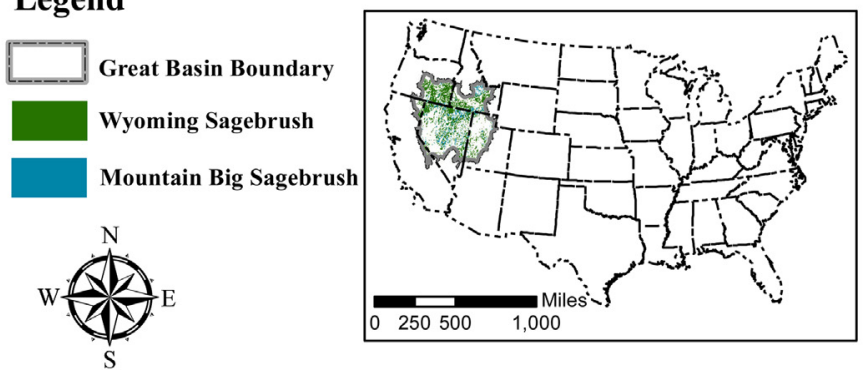

Fig. 1. Geographical distribution of Sagebrush plant communities in the Great Basin.

We capture rangeland ecosystem dynamics in the WSS and MBS systems using an approach based on the state-and-transition model (STM) framework from rangeland ecology (Stringham et al., 2003). The STM framework has been used to describe rangeland ecosystems in North America (Bagchi et al., 2012; Bashari et al., 2008; Knapp et al., 2011) and throughout the world (Asefa et al., 2003; Chartier and Rostagno, 2006; Sankaran and Anderson, 2009; Standish et al., 2009). In this framework, an ecosystem is described as being in one of several ecological states that are separated by ecological thresholds. In rangeland ecosystems, transitions between ecological states can be triggered by natural events such as drought, wildfire, and invasive plants, or by human activities such as excessive livestock grazing. Moreover, transitions can only be reversed with active (and often expensive) management effort (Briske et al., 2006; Mclver et al., 2010). More degraded states are typically less likely to be rehabilitated with management effort, while the healthier states are more resilient and resistant to transition to degraded states (Brooks and Chambers, 2011). The STM framework allows us to characterize ecological dynamics in the WSS and MBS systems, as well as the role of wildfire as a catalyst for transitions between states. Depending on the ecological state, wildfire can be a restorative force that helps to maintain ecosystem function within a desirable 
ecological state, or be a destructive force that moves the ecosystem to less desirable ecological states.

Our simulation model accounts for two main objectives of fuel treatments (Kline, 2004; Reinhardt et al., 2008). First, fuel treatments aim to reduce fuel loading and fuel characteristics to lessen wildfire severity, and thus the expected costs of damages and wildfire suppression. Second, fuel treatments attempt to restore health and resiliency to ecosystems. Accounting for these two objectives of fuel treatments implies that in our simulation the appropriate suite of treatment methods varies by ecological state. For example, in relatively healthy ecological states, fuel treatments involve mechanical removal of decadent sagebrush and/or native conifers. Conversely, in degraded ecological states where invasive annual grasses are present, fuel treatments involve both fuel reduction and rehabilitation through herbicide application and reseeding with desired plant species. The appropriate suites of treatments for each ecological state considered in the simulation are described in Section 2.2.

The success or failure of fuel treatments in sagebrush ecosystems is determined in large measure by whether ecological thresholds between states have been crossed (McIver et al., 2010). This is problematic because it is often difficult for even experienced rangeland ecologists to determine with certainty whether an ecosystem has crossed a threshold between states. This uncertainty can be costly because treatment methods that are appropriate on one side of a threshold may be ineffective or even ecologically destructive after the threshold has been crossed. In addition, in situations where crossing a threshold involves a cost either in terms of a reduction in ecological goods and services (including higher expected wildfire suppression cost) or more expensive/less effective treatment options, uncertainty about whether or not the thresholds has been crossed may cause land managers to treat in circumstances where treatment is either unnecessary or could be delayed at no cost. Our model allows us to analyze how uncertainty about whether or not an ecological threshold between states has been crossed influences the economic efficiency of fuel treatment This information is a valuable contribution to recent rangeland ecology research that aims at improving land managers' ability to accurately determine whether their land has crossed a threshold before undertaking treatment (Mclver et al., 2010).

We report all results on a per-acre basis, in contrast with the previous literature that has evaluated benefits and costs of fuel treatment at larger spatial scales (Loomis et al., 2002; Mercer et al., 2007; Epanchin-Niell et al., 2009). Assumptions and parameters are chosen so that our per-acre results are scalable to larger spatial scales. As such, relative to the previous literature, our analysis is more directly relevant to analyzing the economic efficiency of specific fuel treatment projects, which in practice are often small and targeted (100 acres, 500 acres, etc.; see Rideout and Omi, 1995). In addition, reporting results in per-acre terms has the advantage that it allows us to more readily consider how benefits and cost of fuel treatment differ depending on ecological condition, treatment costs, wildfire-return interval, and other factors, and to address the question of optimal treatment timing given the dynamics of rangeland ecosystems. In particular, recent studies have suggested that present-day fire return intervals in sagebrush ecosystems are shorter than historic averages as a result of invasive plants, changes in disturbance regimes, climate change, and other factors (Baker, 2009; Romme et al., 2009). For this reason, we examine how the economic efficiency of fuel treatment will change as a result of current and anticipated changes in wildfire frequency. In addition, we analyze the relationship between the economic efficiency of fuel treatment, fuel treatment success rates, and fuel treatment costs. This information is necessary to evaluate the economic benefits from applied research in rangeland ecology aimed at improving treatment success rates and lowering treatment costs.

Where the literature reasonably supports ranges of model parameters and assumptions, we chose parameters and assumptions so as not to overstate the benefits or understate the costs of fuel treatment. As such, this article provides conservative estimates of the net benefits of fuel treatment. Three sets of assumptions contribute to our estimates being lower-bounds of the net benefits of fuel treatment. First, for reasons explained in detail below, the wildfire suppression costs data available for use in this study omit wildfire suppression expenditures by local and state agencies, thereby understating the full cost of wildfire suppression. Thus the benefits of fuel treatment, which we measure as the difference in the expected present value of cumulative wildfire suppression costs with and without treatment, will also be understated. Second, our analysis considers wildfire suppression costs savings as the only benefit of fuel treatment. We do not include other benefits of fuel treatment, including reductions in wildfire damage to private property and public infrastructure, and improvements in wildlife habitat, forage for livestock, recreation opportunities, erosion control, and other ecosystem goods and services. In many circumstances, maintenance of these benefits may motivate fuel treatment as much as reducing wildfire suppression costs. ${ }^{5}$ Third, our analysis considers variable, but not fixed fuels treatment costs. ${ }^{6}$ By focusing on variable costs, our analysis is relevant for the marginal decision of whether it is economically efficient to treat an additional acre. For a specific fuel treatment project, the per-acre expected benefits from treatment must be large enough to justify undertaking the fixed costs. Our estimates of variable treatment costs are conservative (likely do not understate costs) in that we do not account for potential reductions in variable costs related to returns to scale in fuel treatment application size that have been identified in the literature (Rummer, 2008). An important implication of having understated the benefits of fuel treatments is that while our results allow us to conclude that treatment is economically efficient under certain conditions, we are not able to conclude that treatment is not efficient in others.

\section{Material and methods}

\subsection{Ecological dynamics: stylized state-and-transition models}

As indicated in the Introduction, we model the WSS and MBS ecosystems using the state-and-transition model (STM) framework from rangeland ecology. The WSS and MBS systems are broad ecological classifications that refer to several different ecological sites, each of which can be represented by its own STM (SRM, 1989). The economic data (e.g., wildfire suppression costs), however, are organized according to these broad classifications. For this reason, rather than presenting results for specific ecological sites in the WSS and MBS systems, we analyze two "stylized" STMs that are intended to be broadly representative of ecological sites found in these two systems. Important to this study, our STMs incorporate the effects of invasive annual grasses on ecological dynamics and fire regimes. This section describes the stylized STMs for the WSS and MBS systems that are used in our simulation.

\footnotetext{
${ }^{5}$ We also do not consider that fuel treatments may damage ecosystem goods and services. For example, prescribed wildfires create smoke, risk escaping their intended boundaries, and heavy equipment used for mechanical fuel removal may lead to soil compaction and increased erosion.

${ }^{6}$ Fixed costs of fuel treatment include administrative costs of project planning and compliance, transporting equipment to and from the treatment site, and equipment maintenance and depreciation. Variable costs include labor and materials on a per acre basis, after the fixed costs have been committed.
} 


\subsubsection{Wyoming Sagebrush Steppe (WSS) system}

As is illustrated in Fig. 2a, our stylized STM for the WSS system consists of three ecological states. Perennial grasses and sagebrush with a small presence of invasive annual grasses characterize the "healthiest" state, which we refer to as WSS-1. Wildfire and fuel treatment maintain the system in WSS-1; however, without wildfire or treatment, a moderate ecological disturbance such as excessive spring livestock grazing will cause the system to transition over time from WSS- 1 to a new ecological state, WSS-2. WSS-2 is characterized by overgrown "decadent" sagebrush with reduced perennial grasses and increased annual grasses. Wildfire in WSS-2 is more intense and more expensive to suppress than wildfire in WSS-1. The transition from WSS- 2 to WSS- 1 is reversible only with rehabilitation effort, and the success of this effort is uncertain. Moreover, because of the loss of perennial plant vigor and the presence of annual grasses, wildfire or treatment failure in WSS-2 causes the system to transition to WSS-3. In WSS-3, invasive annual grasses are the dominant species, wildfires occur frequently, and the system can only be rehabilitated to WSS-1 with costly treatments with very low success rates.

\subsubsection{Mountain Big Sagebrush (MBS) system}

Our stylized STM for the MBS system consists of three ecological states with the first state having two phases (Fig. 2b). Perennial grasses and sagebrush with minimal presence of invasive annual grasses characterize MBS-1a. Naturally occurring rangeland fire and fuel treatments maintain the system in MBS-1a; however, if the system remains MBS-1a for a long period without fire or fuel management, it will transition into the early stages of pinyon-juniper expansion, a new phase within the MBS-1 state that we refer to as MBS- $1 \mathrm{~b}$. The transition to MBS- $1 \mathrm{~b}$ can be reversed with rehabilitation effort, and fire in MBS-1balso restores the system to MBS-1a. Without fire or fuel treatment, the system will eventually transition from MBS-1b to a closed-canopy pinyon-juniper state,
Table 1a

Treatment costs: Wyoming Sagebrush Steppe (\$000 in 2010 dollars; 000s of acres).

\begin{tabular}{|c|c|c|c|}
\hline \multirow{3}{*}{$\begin{array}{l}\text { Treatment method } \\
\text { and cost (\$/acre) }\end{array}$} & \multicolumn{3}{|l|}{ Ecological state } \\
\hline & \multirow{2}{*}{$\begin{array}{l}\text { WSS-1 } \\
\text { Shrubs and } \\
\text { perennial grasses }\end{array}$} & \multirow{2}{*}{$\begin{array}{l}\text { WSS-2 } \\
\text { Decadent sagebrush } \\
\text { with annual grasses }\end{array}$} & \multirow{2}{*}{$\begin{array}{l}\text { WSS-3 } \\
\text { Invasive annual } \\
\text { grass dominated }\end{array}$} \\
\hline & & & \\
\hline Prescribed fire & $\$ 19.50$ & NA & $\$ 19.50$ \\
\hline Brush management & NA & $\$ 60.22$ & NA \\
\hline Herbicide $^{\mathrm{a}, \mathrm{b}}$ & NA & $\$ 51.64$ & $\$ 51.64$ \\
\hline Reseeding $^{\mathrm{C}}$ & NA & $\$ 93.55$ & $\$ 93.55$ \\
\hline Total & $\$ 19.50$ & $\$ 205.35$ & $\$ 164.69$ \\
\hline
\end{tabular}

${ }^{\text {a }}$ NRCS offers a range of herbicide costs to cover a variety of application methods, herbicide, herbicide type, dosage and vegetation conditions. Herbicide application method depends on size of area being treated, with fixed wing common for large areas ( $\$ 12.63$ per acre) and ground rig ( $\$ 33.35$ per acre) more common for smaller areas. Our baseline simulation assumes ground rig application with herbicide cost of $\$ 18.29$ per acre. In order to be conservative about total herbicide cost, we use the ground rig application cost.

b The herbicide Tebuthiuron ("spike") is the most common method to control sagebrush on western rangelands including Utah (Julie Suhr Pierce, NRCS Utah personal communications).

${ }^{c}$ NRCS offers a range of seeding costs to cover a variety of dispersal methods (aerial, ground rig, range drill) and ground preparation (none, ripper, ripper and range disk, and ripper, range disk, furrowing, and Dixie harrow). Our baseline simulation assumes ground rig dispersal and \$10 per acre for seeding costs.

MBS-2, with minimal to no native perennial grasses and invasive annual grasses dominating in the understory. MBS-2 is characterized by less frequent but far more costly wildfires relative to MBS1a or MBS-1b. A system in MBS-2 can be rehabilitated to MBS-1a only with costly management action, the success of which is uncertain. If wildfire occurs or a treatment fails in MBS-2, the system immediately transitions to MBS-3, the annual grass dominated state. As in the WSS system, once invasive annual grasses dominate the system, wildfires are larger and occur more frequently. MBS-3

a

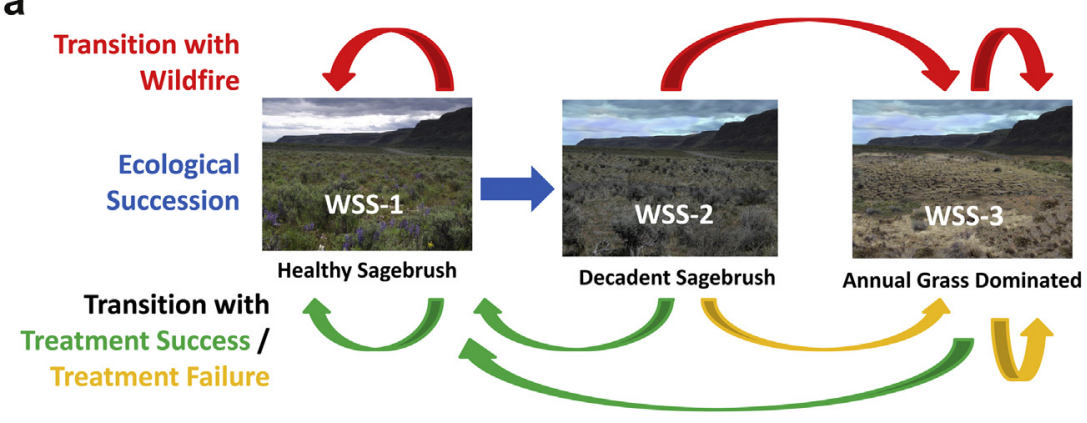

b

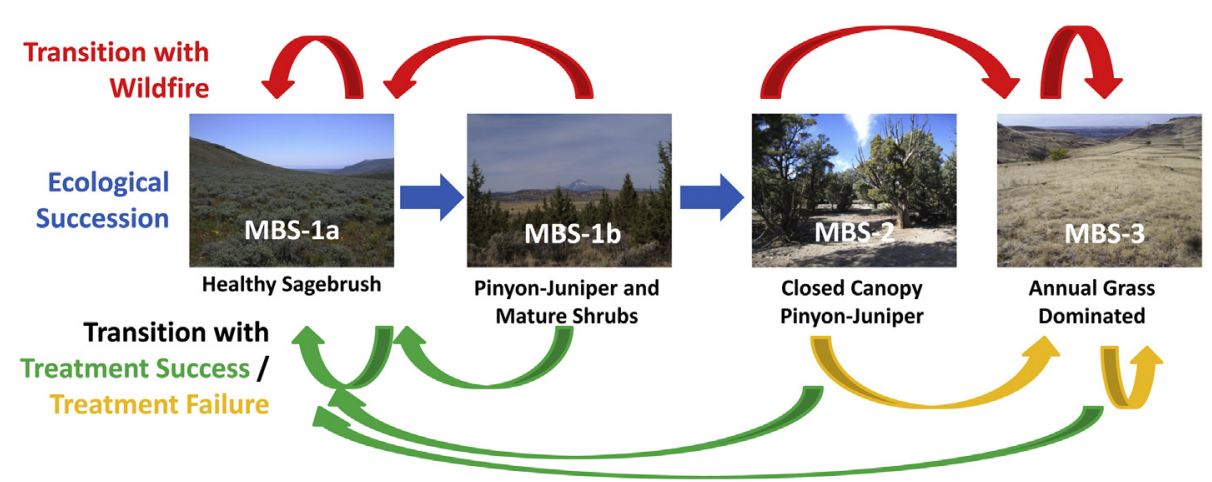

Fig. 2. (a) Wyoming Sagebrush Steppe stylized state-and-transition model. (b) Mountain Big Sagebrush stylized state-and-transition model. 
Table 1b

Treatment cost: Mountain Big Sagebrush (\$000 in 2010 dollars; 000s of acres).

\begin{tabular}{|c|c|c|c|c|}
\hline \multirow{3}{*}{$\begin{array}{l}\text { Treatment method } \\
\text { and cost (\$/acre) }\end{array}$} & \multicolumn{4}{|l|}{ Ecological state } \\
\hline & \multirow{2}{*}{$\begin{array}{l}\text { MBS-1a } \\
\text { Shrubs and } \\
\text { perennial grasses }\end{array}$} & \multirow{2}{*}{$\begin{array}{l}\text { MBS-1b } \\
\text { Pinyon-juniper, } \\
\text { shrubs and } \\
\text { perennial grasses }\end{array}$} & \multirow{2}{*}{$\begin{array}{l}\text { MBS-2 } \\
\text { Closed-canopy } \\
\text { pinyon-juniper } \\
\text { with annual grass }\end{array}$} & \multirow{2}{*}{$\begin{array}{l}\text { MBS-3 } \\
\begin{array}{l}\text { Invasive annual } \\
\text { grass dominated }\end{array}\end{array}$} \\
\hline & & & & \\
\hline Prescribed fire & $\$ 19.50$ & $\$ 45.50$ & NA & $\$ 19.50$ \\
\hline Brush management $^{\mathrm{a}}$ & NA & NA & $\$ 60.22$ & NA \\
\hline Herbicide $^{\mathrm{b}}$ & NA & NA & $\$ 51.64$ & $\$ 51.64$ \\
\hline Reseeding $^{\mathrm{b}}$ & NA & NA & $\$ 93.55$ & $\$ 93.55$ \\
\hline Total & $\$ 19.50$ & $\$ 45.50$ & $\$ 205.35$ & $\$ 164.69$ \\
\hline
\end{tabular}

a The most common method to remove undesired pinyon-juniper trees is "chaining" (Julie Suhr Pierce, NRCS Utah - personal communications). More expensive brush

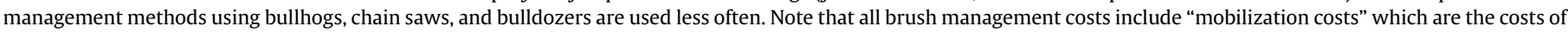

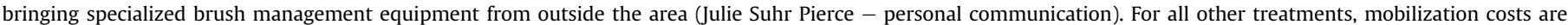
assumed to be minimal and are included in per acre costs.

b See Table 1a for details on the cost information for herbicide and reseeding.

can only be rehabilitated to MBS-1a through costly treatments with very low success rates.

\subsection{Data and parameters}

The stylized STMs in Fig. 2 are numerically implemented to simulate the benefits of fuel treatment. This section describes the parameters and data used in our model. Tables $1-4$ summarize all model parameters and data described in this section, including treatment costs, suppression costs, wildfire frequencies, and the transitions between ecological states in the WSS and MBS systems.

\subsubsection{Fuel management treatments}

We assume that the appropriate suite of fuel treatments and hence, per-acre treatment costs, varies by ecological state in the WSS and MBS systems. Appropriate fuel treatments include prescribed fire in the healthiest states, and mechanical removal of overgrown vegetation by mastication, chaining, and chain saws in degraded states. In all but the healthiest states, fuel treatments are followed by rehabilitation treatment, which involves herbicide application and reseeding with desired species that can compete with invasive annual grasses. Information on treatment costs were obtained from the 2011 "USDA Natural Resources Conservation Service Utah Conservation Practice Cost Data." This database contains the typical costs of conservation practices in Utah in 2011, including per-acre costs for the methods used in our simulation. Tables $1 \mathrm{a}$ and $1 \mathrm{~b}$ give fuel treatment costs in each state in the WSS and MBS systems.

The results of fuel treatment are uncertain (Mclver et al., 2010). For this reason, we model treatment success as probabilistic. Because there is substantial debate among rangeland ecologists about treatment success rates given the complexity of the relationship between treatment success rates and factors such as precipitation, soil structure and timing of treatments, the default success rates used in this simulation (Tables $4 \mathrm{a}$ and $4 \mathrm{~b}$ ) were chosen to be rough approximations under typical conditions in WSS and MBS systems. We evaluate the sensitivity of our results to treatment success rates in Section 3.3.

\subsubsection{Wildfire suppression costs}

Since the benefit of treatment is measured in terms of fire suppression cost averted, per-acre suppression costs represent the most important set of parameters in our model. We use data for 400 wildfires occurring from 1995 through 2007 in USFS Region 4, the Intermountain Region (which includes Wyoming, Utah, Idaho, Nevada, and portions of Colorado and California), that are compiled according to the procedure described in Gebert et al. (2007). The available data for wildfire suppression expenditures do not include a variable that directly identifies STM state at the site of each fire; however, the data do include the National Fire Danger Rating System (NFDRS) fuel model category that is used by USFS, BLM, and other agencies to evaluate wildfire suppression strategy during a wildfire event. The correspondence between the ecological states in our stylized STMs for the WSS and MBS systems and the NFDRS fuel models is made based on the vegetation composition descriptions and is summarized in Table $2 .^{7}$ In the simulation, a random draw from a state-specific sample of per-acre wildfire suppression expenditures is taken each time a wildfire occurs. In order for our per-acre suppression cost distributions to reflect the fact that a given acre is more likely to burn in a large fire than in a small fire, we draw from a weighted distribution of per-acre wildfire suppression costs, with wildfire size used as weights. ${ }^{8}$ Tables $3 a$ and $3 \mathrm{~b}$ summarize wildfire size and suppression costs for each state in the WSS and MBS systems.

The wildfire suppression cost data used in this article likely understate actual per-acre wildfire suppression costs for two reasons. First, the data include only wildfires of over 100 acres (300 acres after 2003) that "escaped" initial suppression efforts by local and state agencies. Because smaller wildfires tend to have larger per-acre suppression costs than larger wildfires, their exclusion implies that fires with higher per-acre costs may be underrepresented in the distributions of per-acre wildfire suppression costs that we draw from in our simulation. The magnitude of the understatement of treatment benefit, however, is likely to be small because the vast majority of burned acres are burned in large wildfires. In the data available through the Western Great Basin Coordinating Center on all wildfires in the western Great Basin between 2000 and 2007, "escaped" wildfires account for $99.7 \%$ of acres burned in WSS-1, 97.0\% in WSS-2, and 98.9\% in WSS-3. Similar patterns are observed in the MBS system.

\footnotetext{
${ }^{7}$ We match each state in the WSS and MBS models with NFDRS fuel model categories using Hal E. Anderson's (1982) “Aids to Determining Fuel Models for Estimating Fire Behavior." MBS-1a (over 6500 feet) and WSS-1 (between 4700 and 6500 feet) correspond to NFDRS fuel models T and L (perennial grasses with some shrubs). WSS-2 (mature shrub canopy) corresponds to NFDRS fuel model B. WSS-3 and MBS-3 (invasive annual grass dominated) correspond to NFDRS fuel model A. MBS-1b (PJ with mature shrubs) corresponds to NFDRS fuel model C. MBS-2 (Closed-canopy PJ) corresponds to NFDRS fuel model F.

8 The weighting procedure was necessary because per-acre wildfire costs in our data are much larger for smaller wildfires than for large wildfires. The correlation coefficient between wildfire size and per-acre suppression costs is -0.1465 for our sample of 400 wildfires.
} 
Table 2

Wildfire suppression costs ( $\$ 000$ in 2010 dollars; 000s of acres).

\begin{tabular}{|c|c|c|c|c|c|c|c|}
\hline Ecological state & NFDRS fuel model $^{\mathrm{a}}$ & No. obs & Avg. \$/fire ${ }^{b}$ & Total expenditure (\$) & Avg. acres/fire & Total acres burned & Avg. \$/acre ${ }^{c}$ \\
\hline Full sample & & 400 & 1715.4 & $686,145.4$ & 6.8 & 2725.3 & 251.8 \\
\hline WSS-1 & $\mathrm{T}$ and $\mathrm{L}$ & 43 & 441.9 & $19,003.7$ & 2.3 & 100.0 & 190.1 \\
\hline WSS-2 & $\mathrm{B}$ & 14 & 844.1 & $11,817.6$ & 1.1 & 15.0 & 788.7 \\
\hline WSS-3 & A & 12 & 1314.8 & $15,777.5$ & 12.9 & 154.2 & 102.3 \\
\hline MBS-1a & $\mathrm{T}$ and $\mathrm{L}$ & 22 & 627.1 & $13,795.5$ & 2.3 & 49.8 & 276.8 \\
\hline MBS-1b & $\mathrm{C}$ & 21 & 840.0 & $17,639.7$ & 2.3 & 49.0 & 359.8 \\
\hline MBS-2 & $\mathrm{F}$ & 9 & 723.8 & 6514.1 & 1.5 & 13.6 & 478.6 \\
\hline MBS-3 & A & 4 & 5146.5 & $20,586.0$ & 13.4 & 53.4 & 385.3 \\
\hline
\end{tabular}

a See text for discussion of National Fire Danger Rating System (NFDRS) fuel models.

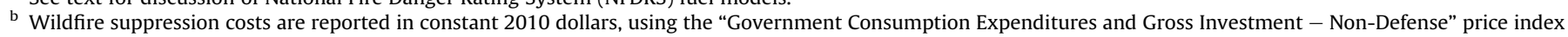

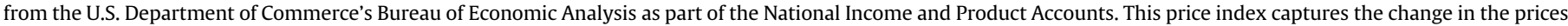
relevant for wildfire suppression costs (e.g., labor, fuel, and mechanical equipment costs).

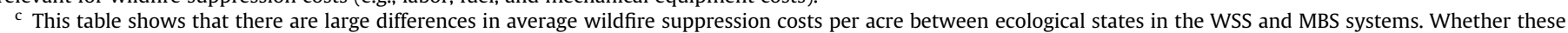

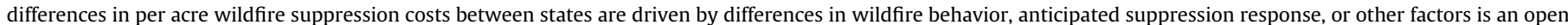

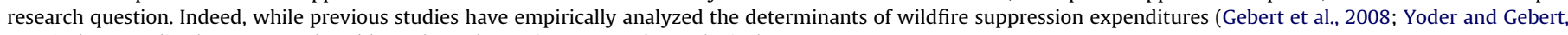
2012), these studies have not analyzed how these determinants vary by ecological state.

Second, our wildfire suppression expenditures are understated for each of the 400 fires in our sample of federal fire suppression costs. Presumably, some resources used for wildfire suppression are also provided by state and local agencies. However, because wildfire suppression expenditure data from local and state agencies are not specifically available on a fire-by-fire basis, we were not able to include these suppression costs in our analysis. The data used in our analysis include wildfire suppression expenditures incurred only at the federal level by the U.S. Forest Service for the years 1995-2003, and expenditures incurred by both the U.S. Forest Service and the Department of Interior for the years 2004-2007. Since total suppression expenditures are understated for each of the 400 fires in our sample, the per-acre wildfire suppression costs used in our simulation underestimates the true per-acre costs. However, the magnitude of this understatement is likely to be small because either the U.S. Forest Service or the U.S. Department of Interior was the "lead protection agency" (or "recorded protection agency") for the vast majority of the 400 fires in our dataset. ${ }^{9}$ U.S. Forest Service Rocky Mountain Research Station has determined that, on average, the U.S. Forest Service assumes over $90 \%$ of total suppression cost for wildfires where it is the lead protection agency (Gebert et al., 2007).

\subsubsection{Wildfire frequency}

Wildfire is modeled as a stochastic event that may or may not occur in a given year. We use information on fire frequency in terms of wildfire-return intervals, or average number of years between two fires, to simulate stochastic wildfire occurrences. Specifically, we assume that the annual probability of a wildfire in each state in the WSS and MBS systems is the reciprocal of the wildfire-return intervals reported in the "LANDFIRE Rapid Assessment Vegetation Models," which are available through the USFS's Fire Effects Information System. This is equivalent to assuming that wildfires occur according to a geometric distribution (i.e., the probability of a wildfire is constant and independent across years). We use information from the "Wyoming Sagebrush Steppe" LANDFIRE model for our WSS system (Limbach, 2011), and from the "Mountain Big Sagebrush with Conifers" LANDFIRE model for our MBS system (Major et al., 2011). Wildfire-return intervals for the annual grass dominated states (WSS-3 and MBS-3) are the mean of the wildfire-

\footnotetext{
${ }^{9}$ In particular, between 1995 and 2003, the U.S. Forest Service was the lead protection agency for 96\% of wildfires in our dataset; between 2004 and 2007, either the U.S. Forest Service or the U.S. Department of Interior was the lead protection agency for $88 \%$ of wildfires in our dataset.
}

return intervals for annual grass dominated rangeland reported in Whisenant (1990) and Stringham and Freese (2011). Tables 3a and $3 \mathrm{~b}$ report annual wildfire probabilities used in the simulation for the WSS and MBS systems. We assume that in any year either the entire acre burns or none of the acre burns. This assumption does not change the equivalence between the wildfire-return intervals implied by our model and the wildfire-return intervals reported in the LANDFIRE models.

\subsubsection{Transitions between ecological states}

We assume that the WSS and MBS systems can only remain in the healthiest state (i.e. WSS-1 or MBS-1) for a finite number of years in the absence of management treatment or fire before transitioning to a degraded state (i.e. WSS-2 or MBS-2) through ecological succession. Years to ecological transition used in the simulation for the WSS system were taken from the "Wyoming Sagebrush Steppe" LANDFIRE model; time to transition for the MBS system was taken from the "Mountain Big Sagebrush with Conifers" LANDFIRE model. The number of years to transition from an ecological state to another through ecological succession and the wildfire-return interval in that state reported in the LANDFIRE models and used in this article are calculated independently. This means that the wildfire-return intervals, which are used to calculate the annual probability of wildfire in each state, do not take into account the fact that the site may transition to a new ecological state through succession before a wildfire occurs. ${ }^{10}$ Indeed, for WSS -1 and MBS- $1 b$, the numbers of years to ecological transition through succession (60 years in WSS-1; 44 years in MBS-1b) are less than the wildfire-return intervals ( 107 years in WSS-1; 44 years in MBS-1b). In these cases, on average, the systems will transition to new state through succession before a wildfire occurs.

In addition, we assume that fire in the healthiest state in either the WSS or MBS system resets the system to the earliest stage, or "year 1", in each state, i.e., the stage with the maximum number of years until the system transitions to a degraded state without fire or treatment. For example, if fire occurs in WSS-1, the system returns to "year 1" in WSS-1 with 60 years remaining until the system transitions to WSS-2. If fire occurs in a state where annual grasses

\footnotetext{
10 In the LANDFIRE models, the number of years to transition through succession is the average number of years that a site will remain in an ecological state in the absence of management treatment or wildfire before transitioning to a new state. On the other hand, the wildfire-return interval is the average number of years between wildfires on a site in the ecological state assuming that the site remains in the ecological state.
} 
Table 3a

Wildfire frequency: Wyoming Sagebrush Steppe.

\begin{tabular}{|c|c|c|c|}
\hline & WSS-1 & WSS-2 & WSS-3 \\
\hline & Shrubs and perennial grasses & Decadent sagebrush with annual grasses & Invasive annual grass dominated \\
\hline Wildfire-return interval (years) & 107 & 75 & 9 \\
\hline Annual large fire probability & 0.009 & 0.013 & 0.111 \\
\hline
\end{tabular}

are heavily present in the understory, as is the case in WSS-2 or MBS-2, fire will cause the system to transition to the invasive annual grass dominated state. When the system is in the invasive annual grass dominated state, either WSS-3 or MBS-3, it will remain in this state after wildfire. Tables $4 \mathrm{a}$ and $4 \mathrm{~b}$ summarize information on transition with and without wildfire for the WSS and MBS systems.

\subsection{Simulation methods}

\subsubsection{Simulation methods: approach}

The simulation model considers the progression of the MBS and WSS systems with and without fuel treatments over 200 years. The analysis focuses on differences between these two scenarios in terms of wildfire occurrence, wildfire suppression costs, and other factors. The model treats wildfire occurrences, treatment success given that treatment is undertaken, and per-acre wildfire suppression costs in each year as stochastic parameters. Each run of the model considers the progression of the system in the "treatment" and "no treatment" scenarios with different randomly generated realizations of these stochastic parameters in each year. The stochastic parameters lead to substantial variation in key variables, including wildfire suppression cost savings, between model runs. For this reason, results in this article are reported for 10,000 model runs, and the discussion focuses on the expected values of key variables, which are calculated as the means of these variables over the 10,000 model runs. All results are reported on a per-acre basis. All monetary results are presented in constant 2010 dollars; to calculate net present values, all dollar values are discounted at a constant rate of $3 \%$. A 3\% discount rate is held to be the best estimate of the social time preference of consumers and is used by U.S. federal agencies such as the National Oceanic and Atmospheric Administration, the Department of the Interior, and the U.S. Environmental Protection Agency (Loomis, 2002).

The mechanics of our simulation model are as follows. The state of the system in year $t$ is described by two state variables. First, $S_{t m}^{R}$ is the ecological state in year $t$ (e.g., for the WSS system, $S_{t, m}^{R}$ can be either WSS-1, WSS-2, or WSS-3). The subscript $m$ indicates the $m$ th run of the simulation model. The superscript $R$ indicates the treatment scenario; $R=T$ for a "treatment" scenario and $R=\mathrm{NT}$ for a "no treatment" scenario. Second, $s_{t, m}^{R}$ is the number of years that the system has been in $S_{t, m}^{R}$ in year $t .^{11}$ The random variable $\tilde{P}_{t, m}^{R}$ is equal to 1 if a wildfire occurs in year $t$ and 0 otherwise. The probability that a wildfire occurs in year $t$ (i.e., the probability that $P_{t, m}^{R}=1$ in year $\left.t\right)$ is $p\left(S_{t, m}^{R}\right)$, which depends on the ecological state in year $t$. If a wildfire occurs in year $t$, then the wildfire suppression cost is a random variable, $\widetilde{W} C_{t, m}^{R}$, from a state-specific distribution of per-acre wildfire suppression costs. ${ }^{12}$

\footnotetext{
11 The variable $s_{t, m}^{R}$ is necessary because, as is explained above, the WSS and MBS systems can only remain in the healthiest state for a finite amount of time in the absence of management treatment or wildfire before transitioning to a degraded state.

12 The state-specific annual wildfire probabilities used in the simulation are given in Tables $3 \mathrm{a}$ and $3 \mathrm{~b}$.
}

In the treatment scenario, fuel treatments may take place in years where wildfire does not occur. ${ }^{13}$ Each model run considers a treatment schedule that determines if a treatment occurs in year $t$ given $S_{t, m}^{T}$ and $s_{t, m}^{T}$. The variable $T_{t, m}^{T}$ is equal to 1 if a treatment occurs in year $t$ and 0 otherwise. In years where a fuel treatment is performed (i.e., when $T_{t, m}^{T}=1$ ), the random variable $\tilde{Q}_{t, m}^{R}$ is equal to 1 if the treatment is successful and 0 is the treatment fails. The probability of treatment success in year $t$ is $q\left(S_{t, m}^{R}\right)$, which depends on the ecological state in year $t$. When fuel treatment is performed, a state-specific treatment cost, $T C_{t, m}^{R}$, is incurred. ${ }^{14}$

The state of the system in the following year, $S_{t+1, m}^{R}$ and $s_{t+1, m}^{R}$, depends on the state of the system in year $t, S_{t+1, m}^{T}$ and $s_{t+1, m}^{T}$ on whether or not a wildfire occurred in year $t$, and, in years where treatment takes place, whether or not the treatment is successful. Tables $4 \mathrm{a}$ and $4 \mathrm{~b}$ summarize information on how wildfire and fuel treatment success and failure influence transitions between ecological states for the WSS and MBS systems.

The "net benefits" of fuel treatment are calculated as the present value of the reduction in cumulative wildfire suppression costs resulting from treatment less the present value of total treatment costs. The net benefits for from fuel treatment the $m$ th run of the model is given by

$$
\begin{aligned}
\mathrm{NPV}_{m}= & \sum_{t=1}^{200} \frac{1}{(1+r)^{t}}\left(P_{t, m}^{\mathrm{NT}} \mathrm{WC}_{t, m}^{\mathrm{NT}}\right)-\sum_{t=1}^{200} \frac{1}{(1+r)^{t}}\left(P_{t, m}^{T} \mathrm{WC}_{t, m}^{T}\right. \\
& \left.+T_{t, m}^{T} \mathrm{TC}_{t, m}^{T}\right)
\end{aligned}
$$

where $r$ is the discount rate ( $r=3 \%$ for the results presented in this article) and $P_{t, m}^{R}$ and $W C_{t, m}^{R}, R_{R}=T, N T$, are the realizations of the random variables $\tilde{P}_{t, m}^{R}$ and $\mathrm{WC}_{t, m}^{R}$ in year $t$ in the treatment and no treatment scenarios. The expected value of net benefits is calculated as the mean of net benefits for the 10,000 model runs

$E[\mathrm{NPV}]=\sum_{m=1}^{10,000} \mathrm{NPV}_{m}$

A positive expected value of net benefits implies that it is economically efficient for society to pursue the treatment strategy.

Where to perform treatment on a heterogeneous landscape given a fixed budget can be analyzed by calculating expected benefit-cost ratios for lands in different initial conditions (WSS-1, WSS-2, etc.). Benefit-cost ratios are the appropriate metric for evaluating which types of land should be treated first because, given a fixed budget, net benefits are maximized by treating the land with the highest benefit-cost ratios until the budget is exhausted. The expected benefit-cost of treatment ratio is given by

\footnotetext{
13 The model assumes that the year begins before wildfire season (in the spring) and that wildfire occurs or does no not occur before treatments take place (in the late fall/early winter).

14 As explained above, the state-specific treatment costs used in this simulation are given in Tables $1 \mathrm{a}$ and $1 \mathrm{~b}$ and the state-specific treatment success probabilities are given in Tables $4 a$ and $4 b$
} 
$E[\mathrm{BCR}]=\sum_{m=1}^{10,000}\left[\frac{\sum_{t=1}^{200} \frac{1}{(1+r)^{t}}\left(P_{t, m}^{\mathrm{NT}} \mathrm{WC}_{t, m}^{\mathrm{NT}}\right)-\sum_{t=1}^{200} \frac{1}{(1+r)^{t}}\left(P_{t, m}^{T} \mathrm{WC} C_{t, m}^{T}\right)}{\sum_{t=1}^{200} \frac{1}{(1+r)^{t}}\left(T_{t, m}^{T} \mathrm{TC}_{t, m}^{T}\right)}\right]$

Note that the stochastic parameters lead to variation in key variables across model runs holding the parameter values and the distributions for the stochastic parameters fixed. We report results for the range of outcomes for key variables across model runs given the realization of the stochastic parameters (i.e., wildfire occurrences, treatment success given that treatment is undertaken, and per-acre wildfire suppression costs). In the analysis below, we explore the sensitivity of our results to our assumptions about several key parameters, including treatment costs, treatment success rates, and wildfire frequency.

We choose to build uncertainty about fuel treatment outcomes directly into our model through the inclusion of our stochastic parameters in part because we consider restoration-based fuel treatments. It is widely acknowledged that it is difficult to restore ecosystems, rangeland or otherwise, in a reliable and predictable manner (Sheley et al., 2011). Given this fact, evaluating the net economic benefits of restoration-based fuel treatment requires an economic framework that directly incorporates the probabilistic nature of how ecosystems respond to management. In contrast to our approach, Prestemon et al. (2012) directly build uncertainty about the parameters into their simulation model to estimate the expected economic benefits of mechanical fuel treatments on timberlands in the western United States. In doing so, Prestemon et al. are able to present a range of expected benefits from fuel treatment given the uncertainty about model parameters; however, they are not able to analyze the uncertainty inherent in fuel treatments outcomes.

\subsubsection{Simulation methods: fuel treatment scenarios}

The benefits and costs of fuel treatment are calculated for two cases for the WSS system. First, we assume that (i) one can observe with certainty which state the system is in WSS-1 or WSS-2, and (ii) it is possible to determine how many years the system will remain in WSS- 1 before transitioning to WSS-2. We refer to this scenario as the "certain" threshold case. Second, we relax these two assumptions so that it is not possible to observe whether or not the threshold between WSS-1 and WSS-2 has been crossed, nor is it possible to observe the "location" of the system relative the threshold, i.e. the number of years until the transition from WSS-1 to WSS-2 would occur without wildfire or fuel treatment. These assumptions capture the fact that it is often difficult for experienced rangeland ecologists to determine whether a system has crossed a critical ecological threshold (McIver et al., 2010). We refer to this second scenario as the "uncertain" threshold case. As seen below, optimal treatment schedules differ in the two cases.

The treatment schedule in the WSS system for the certain treatment case is as follows. In WSS-1, treatment is applied in the final year before transition to WSS-2. As is described in Table 4a, the WSS system can only remain in WSS-1 for 60 years in the absence of management treatment or wildfire before transitioning to WSS-2. It follows that it is always optimal to delay treatment in WSS- 1 until just before the systems transitions to WSS- 2 because this strategy delays the cost of treatment and, as treatment is $100 \%$ successful in WSS-1, there is no risk associated with delaying treatment until just before the threshold. Moreover, delaying treatment increases the chances that the system will experience a wildfire, which is beneficial to rangeland health in WSS-1 and resets the system so that there is 60 years until the transition to WSS-2.

In both WSS-2 and WSS-3, transitions between states occur as a result of wildfire or fuel treatment. That the system does not transition without these two factors implies that if it is not economically efficient to treat in the current year in either WSS-2 or WSS-3, then it is never efficient to treat. This also implies that if it is

Table 3b

Wildfire Frequency: Mountain Big Sagebrush

\begin{tabular}{|c|c|c|c|c|}
\hline & MBS-1a & MBS-1b & MBS-2 & MBS-3 \\
\hline & $\begin{array}{l}\text { Shrubs and } \\
\text { perennial grasses }\end{array}$ & $\begin{array}{l}\text { Pinyon-juniper, } \\
\text { shrubs and perennial grasses }\end{array}$ & $\begin{array}{l}\text { Closed-canopy pinyon- } \\
\text { juniper with annual grass }\end{array}$ & $\begin{array}{l}\text { Invasive annual } \\
\text { grass dominated }\end{array}$ \\
\hline Wildfire-return interval (years) & 60 & 50 & 75 & 9 \\
\hline Annual large fire probability & 0.017 & 0.020 & 0.013 & 0.111 \\
\hline
\end{tabular}

Table 4a

Transitions between states: Wyoming Sagebrush Steppe.

\begin{tabular}{|c|c|c|c|}
\hline & \multicolumn{3}{|l|}{ Ecological state } \\
\hline & \multirow{2}{*}{$\frac{\text { WSS-1 }}{\text { Shrubs and perennial grasses }}$} & \multirow{2}{*}{$\begin{array}{l}\text { WSS-2 } \\
\text { Decadent sagebrush with annual grasses }\end{array}$} & \multirow{2}{*}{$\frac{\text { WSS-3 }}{\text { Invasive annual grass dominated }}$} \\
\hline & & & \\
\hline Time to transition $\mathrm{w} / \mathrm{o}$ wildfire & 60 years $\rightarrow$ WSS- $2^{\text {a }}$ & NA & NA \\
\hline Transition with fire & $\rightarrow$ Year 1 in WSS- 1 & $\rightarrow$ WSS-3 & Stay in WSS-3 \\
\hline Successful treatment & $\rightarrow$ Year 1 in WSS- 1 & $\rightarrow$ Year 1 in WSS-1 & $\rightarrow$ Year 1 in WSS- 1 \\
\hline Unsuccessful treatment & No Change & $\rightarrow$ WSS-3 & No Change \\
\hline Prob. of treatment success & 1.00 & 0.500 & 0.025 \\
\hline
\end{tabular}

a 60 years is derived by combining Classes A and B for LANDFIRE model “Wyoming Sagebrush Steppe" (Limbach, 2011). 


\begin{tabular}{|c|c|c|c|c|}
\hline & \multicolumn{4}{|l|}{ Ecological state } \\
\hline & MBS-1a & MBS-1b & MBS-2 & MBS-3 \\
\hline & $\begin{array}{l}\text { Shrubs and perennial } \\
\text { grasses }\end{array}$ & $\begin{array}{l}\text { Pinyon-juniper, shrubs } \\
\text { and perennial grasses }\end{array}$ & $\begin{array}{l}\text { Closed-canopy pinyon- } \\
\text { juniper with annual grass }\end{array}$ & $\begin{array}{l}\text { Invasive annual grass } \\
\text { dominated }\end{array}$ \\
\hline $\begin{array}{l}\text { Time to transition } \mathrm{w} / \mathrm{o} \\
\text { wildfire }\end{array}$ & 129 Years $\rightarrow$ MBS- $^{a}$ & 44 Years $\rightarrow$ MBS- $3^{b}$ & NA & NA \\
\hline Transition with fire & $\rightarrow$ Year 1 in MBS- 1 & $\rightarrow$ Year 1 in MBS-1 & $\rightarrow$ MBS-4 & Stay in MBS-4 \\
\hline Successful treatment & $\rightarrow$ Year 1 in MBS- 1 & $\rightarrow$ Year 1 in MBS-1 & $\rightarrow$ Year 1 in MBS-1 & $\rightarrow$ Year 1 in MBS- 1 \\
\hline Unsuccessful treatment & No change & No change & $\rightarrow$ MBS-4 & No change \\
\hline Prob. of treatment success & 1.00 & 1.00 & 0.500 & 0.025 \\
\hline
\end{tabular}

a 129 years is derived by combining Classes A, B, and C for the LANDFIRE model "Mountain Big Sagebrush with Conifers"(Major et al., 2011).

b 44 years is derived from Class D from the LANDFIRE model “Mountain Big Sagebrush with Conifers”(Major et al., 2011).

economically efficient to treat in WSS-3, then it will be economically efficient to perform treatment immediately following a failed treatment until a successful treatment occurs. Repeated treatments are not an issue in WSS-2 because we assume that treatment in WSS- 2 results in immediate transition to WSS-1 (success) or WSS-3 (failure). A successful fuel treatment applied in either WSS-2 or WSS-3, whereby the system returns to WSS-1, is also followed up by treatment in WSS-1 the year before transition to WSS-2.

The treatment schedule in the MBS system for the certain treatment case is as follows. In MBS-1a and MBS- $1 \mathrm{~b}$, treatment is applied in the final year before transition. As described in Table $4 \mathrm{~b}$, in the absence of treatment or fire, the system remains in MBS-1a for 129 years before transitioning to MBS- $1 \mathrm{~b}$, and remains in MBS-1b for 44 years before transitioning to MBS-2. As in the WSS system, it is always optimal to delay treatment in MBS-1a and MBS1b until just before the system transitions because this strategy delays the cost of treatment, increases the likelihood of beneficial wildfire, and does not reduce the chances of treatment success. In MBS-2 and MBS-3, transitions between states occur as a result of wildfire or fuel treatment. As in the WSS system, this implies that if it is not economically efficient to treat MBS-2 and MBS-3 in the current year, then it will never be efficient to treat; and that if it is economically efficient to treat, then it will be economically efficient to perform treatment immediately following a failed treatment until a successful treatment occurs. Treatments in consecutive years do not arise in MBS-2 because we assume that treatment in MBS-2 results in immediate transition to MBS-1a (success) or MBS3 (failure).

We assume that model parameters are fixed within each state. For example, we assume that treatment costs, the probability that treatment will be successful, annual wildfire probability, and the expected costs of wildfire suppression are the same for every year that the system is in WSS-1. It is reasonable to expect, however, that some of these parameters would be different in the 1st of year of the WSS- 1 system compared to the 59 th year of the WSS- 1 system. We assume that parameters are fixed within each state because we do not know of any sources in the published or unpublished literature that describe how these parameters will change over time with changes in vegetation conditions within a state. When and if this information becomes available, incorporation of parameter changes within states would be a straightforward and interesting extension of the analytical framework presented in this article.

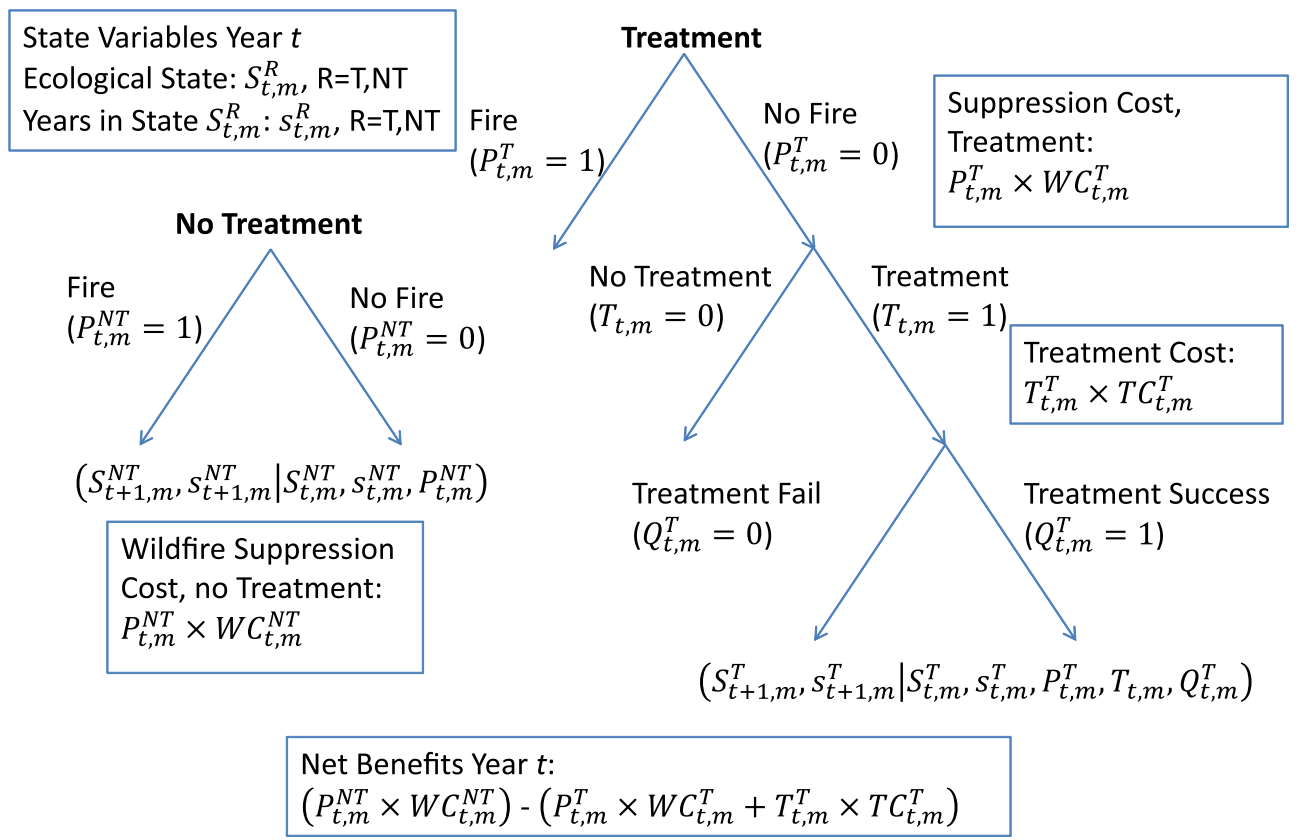

Fig. 3. Net benefits from Fuel Treatment: $m$ th model run, year $t$. 


\section{Results and discussion}

To begin, let us illustrate how the simulation output looks using the results of 10,000 simulation runs when the initial ecological state is WSS- 1 and when no treatment is implemented. Fig. 3 reports the distribution of the 10,000 runs in terms of the total number of wildfires and cumulative suppression costs over the 200 simulation years. Due to the stochastic wildfire, both wildfire numbers and suppression costs exhibit wide distributions. In particular, since the cumulative costs are reported in terms of discounted sum of costs over 200 years, the cost distribution is skewed to the left.

\subsection{Wyoming Sagebrush Steppe: certain threshold}

Table 5 reports simulation results for the certain threshold case, when the initial state of the system is WSS-1, WSS-2, or WSS-3. The certain threshold results reported in Table 5 indicate that, given our assumptions and default parameters, the expected net benefits of treatment are positive only in WSS-1. In particular, expected net benefits from fuel treatment are $\$ 271.70$ per acre in WSS-1, with a benefit-cost ratio of 13.3. Treatment in WSS-1 is economically efficient because it is relatively inexpensive ( $\$ 19.50$ per acre), $100 \%$ successful, and leads to a large reduction in the number of wildfires because it prevents transition of the system to WSS-2 and WSS-3. Fuel treatment is not economically efficient in WSS-2 because the appropriate treatment is expensive ( $\$ 205.35$ per acre) relative to expected benefits from treatment ( $\$ 132.80$ in expected wildfire suppression cost savings). An important reason why expected cost savings are low is that treatment in WSS- 2 is successful only $50 \%$ of the time and the consequences of treatment failure is that the system transitions to WSS-3, which entails more frequent wildfires. This is reflected in that treatment in WSS-2 only leads to a reduction in the number of wildfires from 15.2 to 12.1 over 200 years. In WSS-3, fuel treatment is effective at reducing wildfire suppression costs ( $\$ 139.10$ in expected wildfire suppression costs savings), but given the low probability of treatment success (2.5\%), fuel treatment in WSS-3 is cost prohibitive. The expected net benefits of treatment reported on Table 5 for the WSS-3 system are significant because they find that treatment in WSS-3 is not economically efficient; however, the magnitude of the loss in net benefits from treatment in WSS-3 is inflated because the model predicts that treatment will take place in successive years until a successful treatment occurs even though treatment in WSS-3 is not efficient and should not be pursued in the first place. Not surprisingly, the benefit-cost ratios reported in Table 5 indicate that the land in WSS-1 should be treated first (benefit-cost ratio of 13.3), and that treatment is not economically efficient in either WSS-2 or WSS-3 (benefit-cost ratios less than one).

As is mentioned above, the stochastic parameters in the model lead to substantial variation in key variables, including wildfire suppression cost savings, between the 10,000 model runs used to generate each result. To describe the variation due to the stochastic parameters, the 5th and 95th percentiles for key variables are reported in Table 5. Table 5 reveals that while fuel treatment in WSS-1 has positive expected value of net benefits $(\$ 271.70)$, there are model runs where the net benefits from treatment are much larger than this expected value (the 95th percentile is \$1021.60) and there are model runs where the benefits from treatment are negative (the 5 th percentile is $-\$ 23.50$ ). The runs of the model with negative net benefits are simply runs where the realization of the stochastic parameters is such that the system transitions to WSS-2 without treatment but experience little wildfire and suppression costs, and as such, the treatment does not result in an appreciable, if any, reduction in wildfire suppression costs. These results highlight the limitations of drawing conclusions about the efficacy of fuel treatments in an experimental setting by comparing wildfire activity on a small set of sites, some that have experienced fuel treatments and some that have not. In particular, ex-post analysis will sometimes suggest that treatments had negative net benefits even in circumstances where ex-ante treatments were economically justified on the basis of expected wildfire suppression cost savings.

Treated land in WSS-1 will always remain in WSS-1; in contrast, without treatment, the model predicts that after 200 years the systems will have transitioned to WSS-2 $7.3 \%$ of the time and to WSS-3 $92.7 \%$ of the time. This indicates that treatment in WSS-1 serves to avoid the long-run conversion of the system to an annual grass dominated state (WSS-3). Treated land in WSS-2 is evenly split between WSS-1 and WSS-3 in terms of the ending state after 200 years because of the $50 \%$ treatment success rate; however, the fact that the net benefits of treatment in WSS- 2 are negative means that the model suggests that treatment should not be pursued in WSS-2 despite the fact that it helps prevent the transition to WSS-3. Similarly, repeated treatment in WSS-3 over a 200 -year horizon will almost always lead to the rehabilitation of the land to WSS-1 (98.9\%), but the cost of repeated treatment (expected NPV of $\$ 2526.9$ ) does not justify the reduction in wildfire suppression costs (expected NPV of \$139.1). Hence, despite the fact that repeated

Table 5

Wyoming sagebrush steppe results (\$ per acre; 2010 dollars).

\begin{tabular}{|c|c|c|c|}
\hline & \multicolumn{3}{|l|}{ Initial ecological state } \\
\hline & WSS-1 & \multirow{2}{*}{$\frac{\text { WSS-2 }}{\text { Decadent sagebrush with annual grasses }}$} & \multirow{2}{*}{$\frac{\text { WSS-3 }}{\text { Invasive annual grass dominated }}$} \\
\hline & Shrubs and perennial grasses & & \\
\hline Mean number of wildfires - no treatment & $15.1(0,26)^{\mathrm{a}}$ & $15.2(0,27)$ & $22.2(15,30)$ \\
\hline Mean number of wildfires - with treatment & $1.8(0,4)$ & $12.1(0,28)$ & $6.4(1,17)$ \\
\hline Mean total suppression costs (NPV) - no treatment & $\$ 349.8(\$ 0, \$ 1141.1)$ & $\$ 364.2(\$ 0, \$ 1218.6)$ & $\$ 389.8(\$ 149.6, \$ 703.0)$ \\
\hline Mean total suppression costs (NPV) - with treatment & $\$ 56.0(\$ 0, \$ 250.5)$ & $\$ 231.4(\$ 0, \$ 658.9)$ & $\$ 250.7(\$ 2.8, \$ 607.6)$ \\
\hline Mean wildfire suppression costs savings (NPV) & $\$ 293.8(\$ 0.0, \$ 1043.8)$ & $\$ 132.8(-\$ 430.7 \$ 934.1)$ & $\$ 139.1(\$ 0.6, \$ 418.5)$ \\
\hline Mean number of treatments & $3.1(2,4)$ & $2.0(1,4)$ & $41.8(5,121)$ \\
\hline Mean number of successful treatments & $3.1(2,4)$ & $1.5(0,4)$ & $2.5(1,4)$ \\
\hline Mean treatment costs (NPV) & $\$ 22.1(\$ 19.7, \$ 23.5)$ & $\$ 204.4(\$ 205.4, \$ 209.3)$ & $\$ 2526.9(\$ 469.5, \$ 4974.9)$ \\
\hline Final state - no treatment ${ }^{\mathrm{b}}$ (WSS-1, WSS- 2 , WSS- 3 ) & $0,734,9266$ & $0,731,9269$ & $0,0,10,000$ \\
\hline Final state - with treatment (WSS-1, WSS-2, WSS-3) & $10,000,0,0$ & $4949,0,5051$ & $9885,0,115$ \\
\hline $\begin{array}{l}\text { Mean wildfire suppression costs savings net of } \\
\text { treatment costs (NPV) }\end{array}$ & $\$ 271.7(-\$ 23.5, \$ 1021.6)$ & $-\$ 71.6(-\$ 636.1, \$ 727.8)$ & $-\$ 2782.5(-\$ 4965.1,-\$ 107.5)$ \\
\hline Mean benefit-cost ratio (NPV) & 13.3 & 0.7 & 0.06 \\
\hline
\end{tabular}

a 5 th and 95 th percentiles.

b 'Final State' is the final state of the system (WSS-1, WSS-2, or WSS-3) after 200 years. 
a

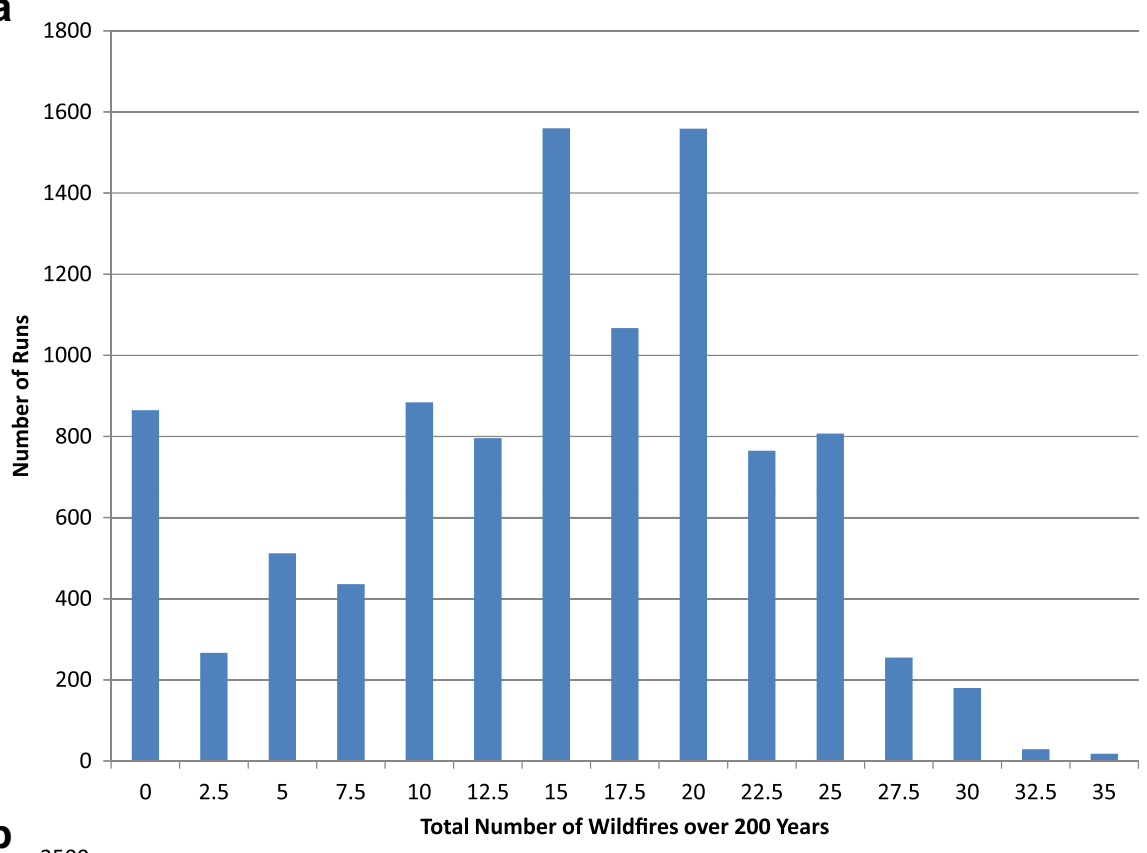

b

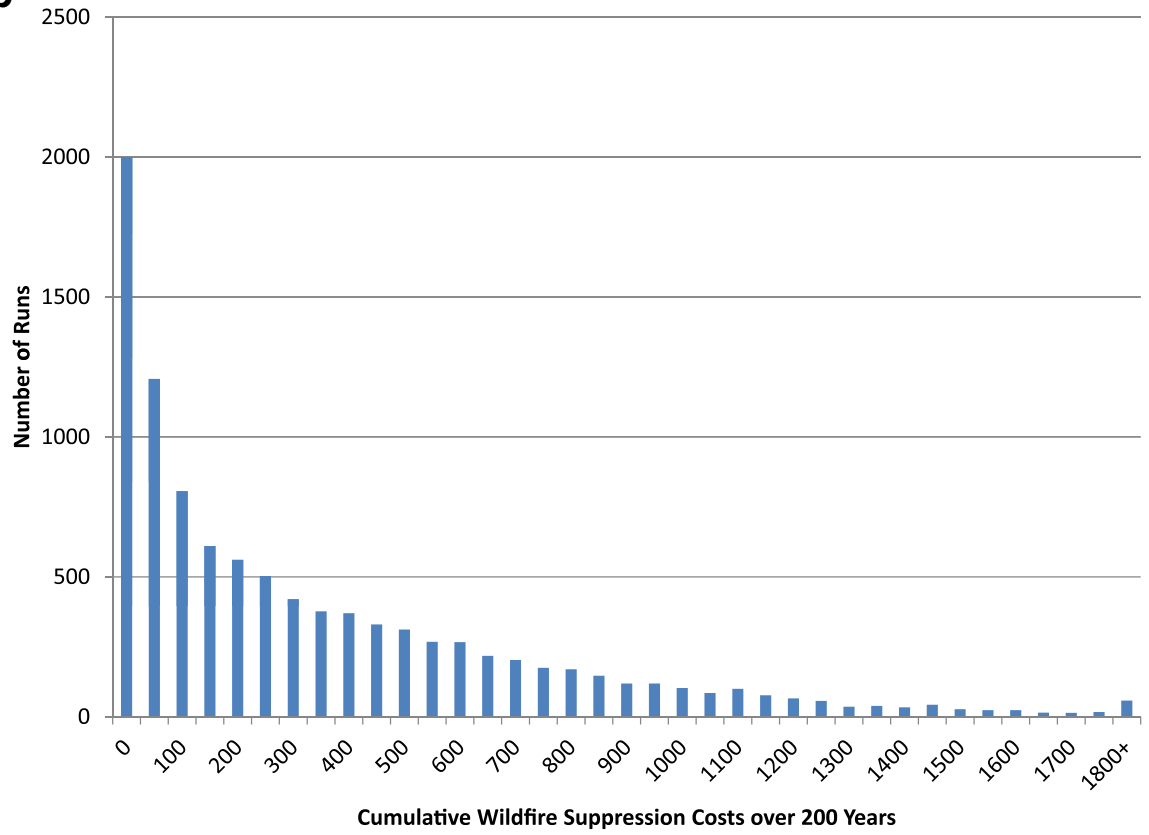

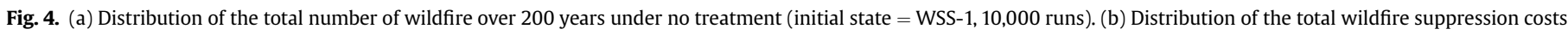
over 200 years under no treatment (initial state $=$ WSS-1, 10,000 runs).

treatment in WSS-3 will lead to close to $100 \%$ rehabilitation, it is still economically efficient for society to leave lands in WSS-3 from the perspective of reduced wildfire suppression expenditure.

\subsection{Wyoming Sagebrush Steppe: uncertain threshold}

In this section we examine how uncertainty about the location of the system relative to the ecological threshold separating WSS-1 and WSS-2 influences the net benefits of fuel treatment, and analyze how improved information regarding threshold location changes the timing and efficiency of fuel treatments. To simulate threshold uncertainty, we assume that the transition between WSS-1 and WSS-2 can occur with equal probability in each year within a range of years. In particular, we consider the cases where the threshold between WSS- 1 and WSS-2 is located with equal probability between the 46th and 75th year, the 31st and 90th year, the 16 th and 105th year, and the 1 st and 120 th year after the system resets to year 1 in WSS-1 (e.g., after a fire in WSS-1 or a successful treatment in any state). The year intervals were selected to bracket year 60 (e.g., the 46th year to 75th year interval is 15 years on either side of year 60), which is the average number of years for a WSS system to transition from WSS-1 to WSS-2 through ecological succession. Fig. 4 describes the expected net benefits of implementing WSS-1 treatment (prescribed fire at $\$ 19.50$ per acre) under the assumption that WSS-1 treatment is successful 100\% of the time if the system is still in WSS-1, but is ineffective when applied 


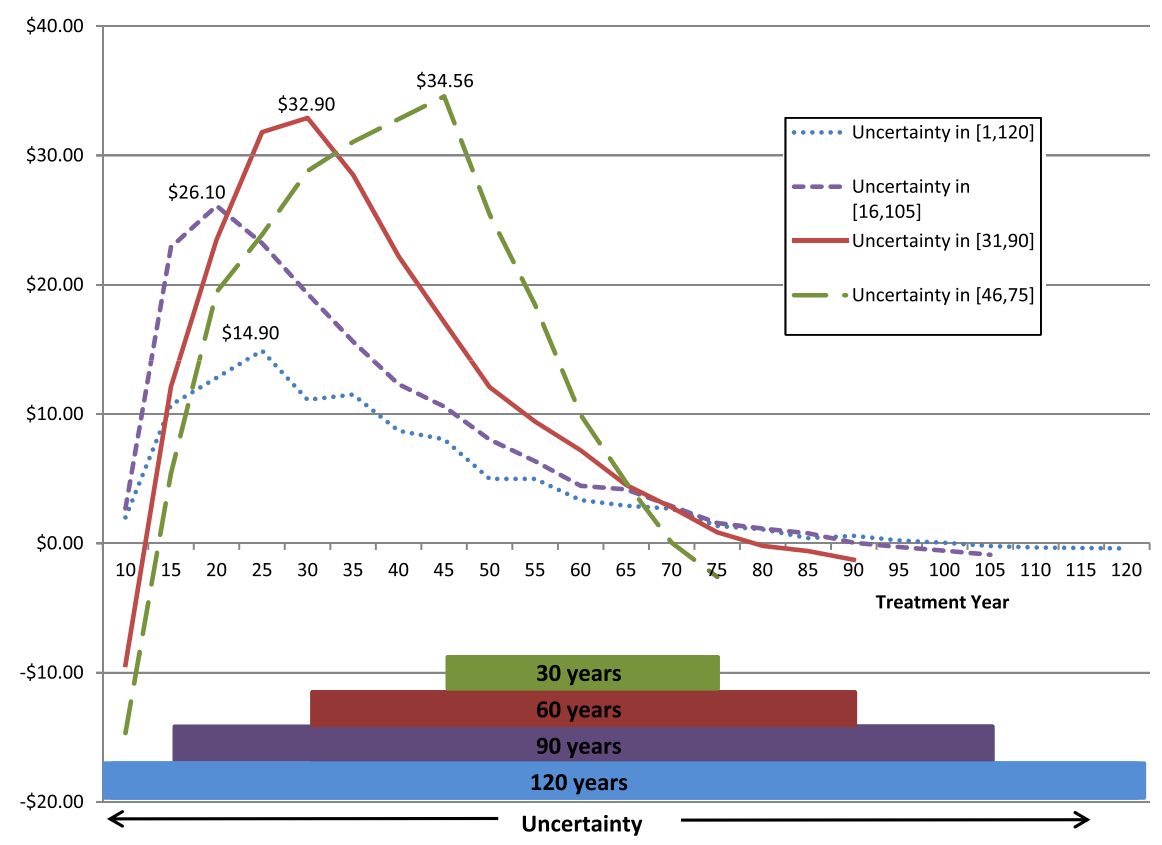

Fig. 5. Expected net benefits from treatment under an uncertain threshold between WSS-1 and WSS-2.

after the system has crossed the (uncertain) threshold to WSS-2. ${ }^{15}$ For the each of the four cases of threshold uncertainty considered in Fig. 4, the expected net benefits of treatment are reported under different assumptions about which year treatment is applied indicated by the horizontal axis, i.e., treatment is applied 20 years after year 1 in WSS-1, treatment is applied 30 years after year 1 in WSS-1, etc. For the each of the four cases, the peak of the graph corresponds to the treatment year that maximizes expected net benefits from treatment given the uncertain threshold.

The uncertain threshold case involves two costs relative to the certain threshold case: the cost of treating too late and the cost of treating too early. Delaying treatment when the threshold is uncertain involves the risk of treating after the system has transitioned to WSS-2. The WSS- 1 treatment is ineffective in WSS-2 and naturally occurring wildfire in WSS- 2 will push the system to WSS3. Treating earlier, on the other hand, involves the cost of bearing the treatment expenses earlier than necessary under a positive discount rate. Treating too early also involves the opportunity cost of a beneficial wildfire that may occur while the system is in WSS-1.

The peaks of the curves in Fig. 4 indicate the expected net benefits associated with the optimal treatment timing under the four cases. For the cases where the threshold to WSS-2 is located between the $46^{\text {th }}$ and $75^{\text {th }}$ year and the $31^{\text {st }}$ and $90^{\text {th }}$ year, the costs associated with delaying treatment (i.e., the risk of crossing the threshold to WSS-2 during the period of delay) are always greater than the benefits of delaying treatment (i.e., the benefits of delaying the cost of treatment and increasing the chance of a beneficial wildfire). For these two cases, the expected net benefits are highest if treatment is implemented in the final year before there is a positive probability of transition to WSS-1. As in the certain threshold case reported in Section 3.1, it is always optimal to delay treatment when it is certain that the system is in WSS-1. For the cases where the threshold is located between the 16th and 105th

\footnotetext{
15 We do not report the results for the case when the appropriate treatment in WSS-2 is used (a combination of herbicide treatment, brush management, and reseeding at $\$ 205.35$ per acre) because we find that WSS-2 treatment is never economically efficient in the uncertain threshold case under the assumptions that it is successful $100 \%$ of the time in WSS- 1 and $50 \%$ of the time in WSS-2.
}

year and 1st and 120th year, the benefits of delaying treatment are greater than the costs in the early period of uncertainty. In part, this reflects the fact that when the period of uncertainty increases in length, the probability of the threshold being crossed each year and, hence, the risk from delaying treatment is smaller relative to when the period of uncertainty is shorter. Net benefits from treatment are highest in year 20 for the case where the threshold is located between the 16th and 105th year and in year 25 in the case with threshold between $1^{\text {st }}$ and 120 th year.

Fig. 4 also demonstrates that the expected net benefits of treatment under optimal timing increase when there is less uncertainty about the ecological threshold separating WSS-1 and WSS-2 (i.e., when the interval over which there is uncertainty about threshold location is shorter). The net benefits are highest when the threshold between WSS-1 and WSS-2 is crossed with certainty in the 61st year ( $\$ 271.70$; see Section 3.1), and decline to $\$ 34.56$ in the case with threshold in 46th-75th year, $\$ 32.90$ in the case with 31 st -90 th year, $\$ 26.10$ in the case with 16th-105th year, and $\$ 14.90$ in the case with 1 st-120th year. Expected net benefits increase when there is less uncertainty about the ecological threshold separating WSS- 1 and WSS- 2 because the reduction in uncertainty allows treatment to be delayed without the risk of treating after the transition to WSS-2.

In each of the four uncertain threshold cases considered in Fig. 5, there is a point beyond which the net benefits become negative and it is no longer economically efficient to apply WSS- 1 treatment. This is because the probability of having crossed the threshold to WSS-2 increases each year, and the probability of a treatment being effective declines each year. For example, for the case where the threshold to WSS-2 is located between the 46th and 75th year, the expected benefit of treatment becomes zero in year 70 , even though there is still a chance that the threshold has not crossed for 5 more years.

\subsection{Treatment costs and treatment success rate}

In this section, we analyze the relationship between fuel treatment success rate, treatment cost, and expected net benefits for the certain threshold case in the WSS system. Evaluating the sensitivity 
of our results to treatment success rates is important in part because there is little information regarding fuel treatment success rates available in the published literature. Not surprisingly, we find that the net benefit from treatment increases monotonically in treatment success rate for treatment in WSS-2 and WSS-3. Recall from Section 3.1 that treatment is not economically efficient in either state under our default assumptions (i.e., a treatment success rate of $50 \%$ in WSS-2 and of $2.5 \%$ in WSS-3). Given our default treatment cost of $\$ 205.35$ per acre, we find that treating in WSS-2 is economically efficient for success rates of $75 \%$ or higher; for WSS-3, treatment is economically efficient for success rates of $52 \%$ or higher at the default cost of $\$ 164.69$ per acre. From this exercise, we conclude that the qualitative results are somewhat sensitive to the treatment success rate in WSS-2 but not in WSS-3. Treatment in WSS-2 may or may not be economically efficient at the success rate within $\pm 50 \%$ of the default value, while economic inefficiency of treatment in WSS-3 is robust in the vicinity of the default treatment success rate. These results also indicate that treatment that attempts to rehabilitate already degraded rangelands to WSS-2 can become economically efficient at sufficiently high treatment success rates, which may be attained through using alternative treatment methods, increasing the application intensity, or applying the results of scientific research aimed at increasing the effectiveness of fuel treatments.

Next, we consider the "break-even" treatment cost for a range of treatment success rates. For given treatment success rate, the break-even treatment cost is defined so that the expected net benefits from treatment predicted by the simulation model are not statistically different from zero at the $10 \%$ level by a two-sided $t$ test. Fig. 6a,b illustrates the "break-even" treatment cost as well as the default treatment cost/success rate combination used in the simulations. The region below the "break-even" curve (the shaded region in Fig. 6a,b) contains all economically efficient treatment cost/success rate combinations given our assumptions. The figures confirm that our default treatment cost/success rate combinations in WSS-2 and WSS-3 fall outside the shaded area, and that

a

$\$ 300.00$
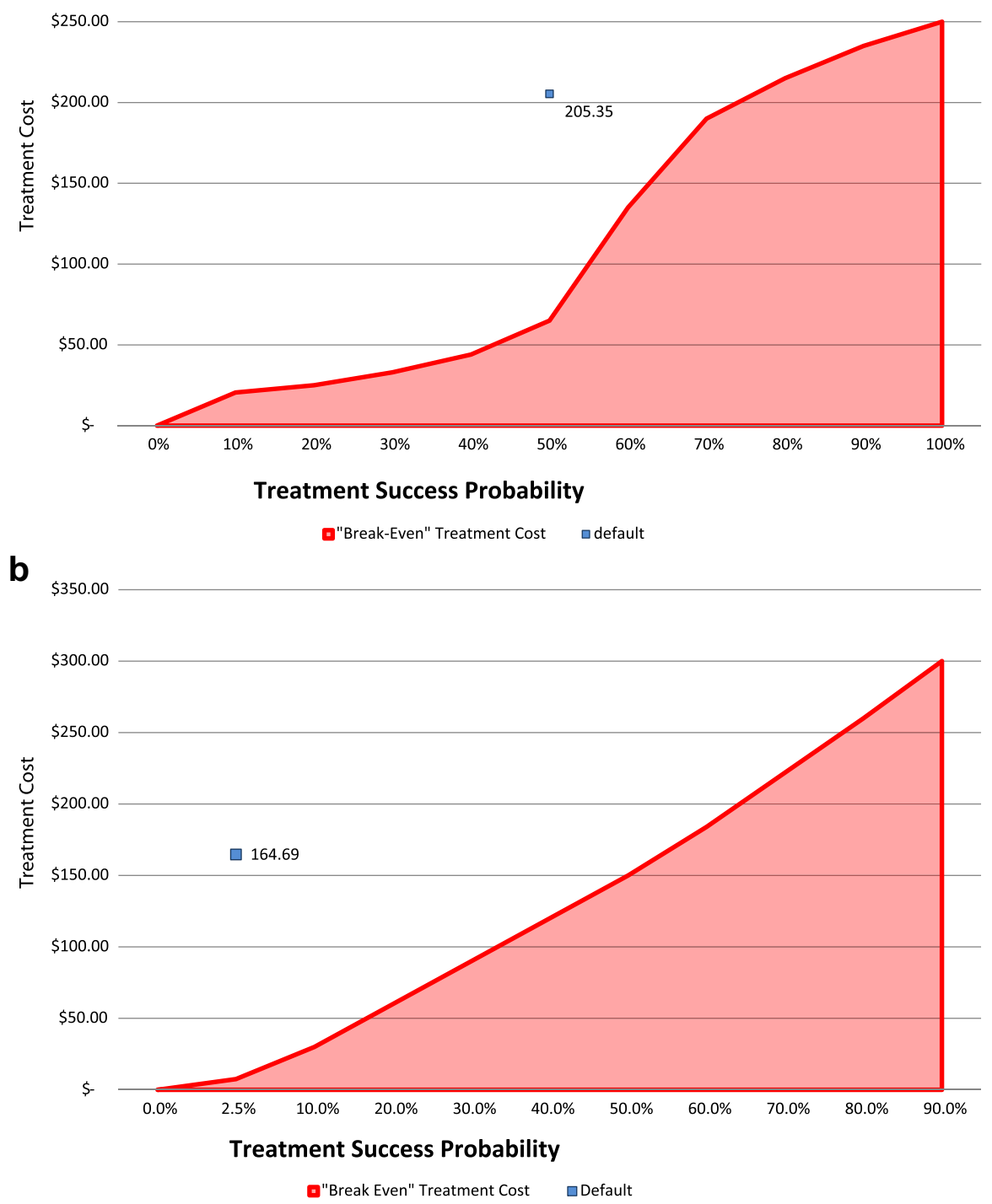

Fig. 6. (a) Break-even treatment costs for given treatment success rates in WSS-2. (b) Break-even treatment costs for given treatment success rates in WSS-3. 
Table 6

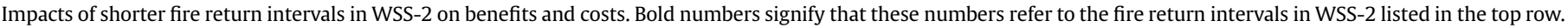

\begin{tabular}{|c|c|c|c|c|c|}
\hline \multirow[b]{2}{*}{ Initial state $=$ WSS-1 } & \multicolumn{5}{|c|}{ Fire return interval in WSS-2 (years) } \\
\hline & 75 & 50 & 25 & 15 & 5 \\
\hline Mean total suppression costs (NPV) - no treatment & $\$ 349.80$ & $\$ 463.90$ & $\$ 662.00$ & $\$ 798.20$ & $\$ 1013.00$ \\
\hline Mean total suppression costs (NPV) - with treatment & $\$ 56.00$ & $\$ 59.10$ & $\$ 57.30$ & $\$ 57.70$ & $\$ 59.20$ \\
\hline Mean treatment costs (NPV) & $\$ 22.10$ & $\$ 22.09$ & $\$ 22.09$ & $\$ 22.08$ & $\$ 22.08$ \\
\hline Mean wildfire suppression costs savings net of treatment costs (NPV) & $\$ 271.70$ & $\$ 382.70$ & $\$ 582.50$ & $\$ 718.50$ & $\$ 931.70$ \\
\hline Mean benefit-cost ratio (NPV) & 13.3 & 18.3 & 27.4 & 33.5 & 43.2 \\
\hline Initial State $=$ WSS-2 & 75 & 50 & 25 & 15 & 5 \\
\hline Mean total suppression costs (NPV) - no treatment & $\$ 364.20$ & $\$ 480.50$ & $\$ 686.50$ & $\$ 832.30$ & $\$ 1051.40$ \\
\hline Mean total suppression costs (NPV) - with treatment & $\$ 231.40$ & $\$ 232.90$ & $\$ 258.80$ & $\$ 278.00$ & $\$ 415.00$ \\
\hline Mean treatment costs (NPV) & $\$ 204.40$ & $\$ 202.92$ & $\$ 198.16$ & $\$ 193.36$ & $\$ 164.69$ \\
\hline Mean wildfire suppression costs savings net of treatment costs (NPV) & $-\$ 71.60$ & $\$ 44.60$ & $\$ 229.50$ & $\$ 360.90$ & $\$ 471.70$ \\
\hline Mean benefit-cost ratio (NPV) & 0.7 & 1.2 & 2.2 & 2.9 & 3.9 \\
\hline
\end{tabular}

Table 7

Mountain Big Sagebrush results (\$ per acre; 2010 dollars).

\begin{tabular}{|c|c|c|c|c|}
\hline & \multicolumn{4}{|l|}{ Initial ecological state } \\
\hline & \multirow{2}{*}{$\begin{array}{l}\text { MBS-1a } \\
\begin{array}{l}\text { Shrubs and perennial } \\
\text { grasses }\end{array}\end{array}$} & \multirow{2}{*}{$\begin{array}{l}\text { MBS-1b } \\
\text { Pinyon-juniper, } \\
\text { shrubs and perennial } \\
\text { grasses }\end{array}$} & \multirow{2}{*}{$\begin{array}{l}\text { MBS-2 } \\
\text { Closed-canopy pinyon- } \\
\text { juniper with annual grass }\end{array}$} & \multirow{2}{*}{$\begin{array}{l}\text { MBS-3 } \\
\text { Invasive annual grass } \\
\text { dominated }\end{array}$} \\
\hline & & & & \\
\hline Mean number of wildfires - no treatment & $6.6(1,18)^{\mathrm{a}}$ & $14.7(0,26)$ & $15.0(0,26)$ & $22.0(15,29)$ \\
\hline Mean number of wildfires - with treatment & $3.4(1,7)$ & $3.4(1,7)$ & $12.8(1,28)$ & $7.5(2,17)$ \\
\hline Mean total suppression costs (NPV) - no treatment & $\$ 273.4(\$ 1.1, \$ 770.2)$ & $\$ 560.7(\$ 0, \$ 1903.3)$ & $\$ 576.2(\$ 0, \$ 1937.4)$ & $\$ 1447.7(\$ 352.5, \$ 2883.6)$ \\
\hline Mean total suppression costs (NPV)- with treatment & $\$ 164.3(\$ 1.3, \$ 539.0)$ & $\$ 158.2(\$ 1.3, \$ 498.2)$ & $\$ 793.0(\$ 5.9, \$ 2443.6)$ & $\$ 894.1(\$ 28.5, \$ 2381.1)$ \\
\hline Mean wildfire suppression costs savings (NPV) & $\begin{array}{l}\$ 109.1 \\
(\$-252.6, \$ 521.2)\end{array}$ & $\begin{array}{l}\$ 402.5 \\
(-\$ 80.9, \$ 1575.9)\end{array}$ & $\begin{array}{l}-\$ 216.8 \\
(-\$ 1885.3, \$ 1183.1)\end{array}$ & $\begin{array}{l}\$ 553.6 \\
(\$ 7.5, \$ 1719.4)\end{array}$ \\
\hline Mean number of treatments & $1.2(1,2)$ & $1.1(1,2)$ & $1.02(1,1)$ & $39.7(3,119)$ \\
\hline Mean number of successful treatments & $1.2(1,2)$ & $1.1(1,2)$ & $0.5(0,1)$ & $1.0(1,1)$ \\
\hline Mean treatment costs (NPV) & $\$ 19.3(\$ 19.5, \$ 19.9)$ & $\$ 44.7(\$ 45.5, \$ 45.7)$ & $\$ 202.5(\$ 205.4, \$ 205.4)$ & $\$ 2886.1(\$ 465.8, \$ 4958.7)$ \\
\hline Final state - no treatment ${ }^{\mathrm{b}}$ (MSS- $1 \mathrm{a},-1 \mathrm{~b},-2,-3$ ) & $5328,394,719,3559$ & $171,6,759,9064$ & $0,0,769,9231$ & $0,0,0,10,000$ \\
\hline Final state - with treatment (MSS- $1 \mathrm{a},-1 \mathrm{~b},-2,-3$ ) & $10,000,0,0,0$ & $9462,538,0,0$ & $4455,2,5258$ & $9182,599,14,205$ \\
\hline $\begin{array}{l}\text { Mean wildfire suppression costs savings net of } \\
\text { treatment costs (NPV) }\end{array}$ & $\$ 89.8(-\$ 272.1, \$ 502.7)$ & $\$ 357.9(-\$ 126.4, \$ 1530.4)$ & $-\$ 419.3(\$ 2090.7, \$ 977.7)$ & $-\$ 2,332.5(-\$ 4927.8, \$ 937.0)$ \\
\hline Mean benefit-cost ratio (NPV) & 5.7 & 9.0 & 1.1 & 0.2 \\
\hline
\end{tabular}

treatment in both states could become economically efficient if either the cost of treatment were lowered or the treatment success rate were increased.

\subsection{Wildfire frequency}

Recent studies suggest that current fire return intervals on sagebrush rangelands are shorter relative to historic averages as a result of invasive plants, changes in disturbance regimes, climate change, and other factors (Baker, 2009; Romme et al., 2009). Because of these current and anticipated changes in wildfire frequency, in this section we reconsider the economic efficiency of fuel treatment for a range of wildfire frequencies for the certain threshold case in the WSS system. We focus on changes in wildfire frequencies in WSS-2 because it is believed that this state has experienced large changes in wildfire frequencies relative to historic averages as a result of annual grass invasion. ${ }^{16}$

\footnotetext{
${ }^{16}$ While there is evidence that invasive annual grasses have reduced wildfirereturn intervals in general on rangeland in the Great Basin of the western United States (Whisenant, 1990; Balch et al., 2013), there is not published evidence that we are aware of that establishes how an increase in the prevalence of invasive annual grasses in the understory of sagebrush dominated state (WSS-2) will influence the wildfire-return intervals. For example, Balch et al. (2013) do not distinguish between "sagebrush steppe" rangeland and "sagebrush steppe" rangeland with a cheatgrass grass as a prominent component of the understory when they establish wildfire-return intervals for sagebrush steppe rangelands.
}

Table 6 lists the mean wildfire suppression costs with and without treatment, mean treatment costs, mean net benefits, and benefit-cost ratios under different fire return intervals in WSS-2 for the cases where the initial state is WSS-1 and WSS-2. The results reported in Table 6 indicate that shorter fire return intervals lead to large increases in the mean wildfire suppression costs without treatment. For example, when the initial state is WSS-1, the mean total suppression cost without treatment increases from $\$ 349.80$ for the default fire return interval in WSS-2 of 75 years to $\$ 463.90$ for a return interval of 50 years and $\$ 662.00$ for a fire return interval of 25 years. This increase in expected wildfire suppression costs without treatment implies that even a small reduction in the fire return interval in WSS-2, say from our baseline of 75 years to 50 years, will make fuel treatments in WSS-2 economically efficient. If, for example, the fire return interval in WSS-2 is shortened to 25 years because of the presence of annual grasses, then the net economic benefits from treatment in WSS-1 are $\$ 582.50$ compared to $\$ 271.70$ under our baseline fire return interval of 75 years; the net economic benefits from treatment in WSS-2 are $\$ 229.50$ compared to $-\$ 71.60$ under our baseline assumptions. We believe that fire intervals of 25 years or less are plausible for WSS-2 when annual grasses dominate the understory. Finally, the benefit-cost ratios in Table 6 indicate that treatment is economically efficient in WSS-2 for wildfire-return intervals in WSS-2 of 50 years or shorter. The results also indicate that for any wildfire-return interval in WSS-2, the benefit-cost ratio is higher 
for treating WSS-1 lands than for WSS-2 lands. This suggests that given a limited budget, land in WSS-1 should receive treatment land in WSS-2 regardless of the wildfire-return interval in WSS-2.

\subsection{Mountain Big Sagebrush: certain threshold}

Table 7 reports the results from the simulation model in the MBS system for the certain threshold case. We find that, given our assumptions and default parameters, the expected net benefits from fuel treatment are $\$ 89.80$ per acre in MBS-1a and $\$ 357.90$ per acre in MBS-1b, and that fuel treatment is not economically efficient in either MBS-2 or MBS-3. These results mirror the results from the WSS system, where fuel treatments are economically efficient only in the healthiest ecological states. As in the WSS system, treatments are efficient in the healthiest states because treatment is $100 \%$ successful, relatively inexpensive, and prevents transition to MBS-2 and MBS-3, which entail frequent wildfires that are expensive to suppress. In MBS-2, average wildfire suppression costs are higher with fuel treatment than without. This counterintuitive result is driven by the consequences of treatment failure in MBS-2, which results in the systems transitioning to MBS-3, the annual grass dominated state, and more frequent wildfire and higher wildfire suppression costs. Because of the high cost of treatment failure in MBS-2, average wildfire suppression costs are lower if treatment is not applied, despite the high cost of wildfire suppression in MBS-2 and the fact that the land will transition to MBS-3 after a wildfire. Similarly, fuel treatment is not efficient in MBS-3, despite the large wildfire suppression cost saving associated with rehabilitation to MBS-1, because of very low treatment success rates and relatively high treatment costs. The average benefit-cost ratio is 5.7 in MBS1a and 9.0 in MBS-1b, which are both smaller than the average benefit-cost ratio in WSS-1 of 13.3. This indicates that on a heterogeneous landscape, land in WSS- 1 should be given priority for fuel treatment, followed by land in MBS-1b then land in MBS-1a.

\section{Conclusions}

In this article we developed a simulation model for evaluating the economic efficiency of fuel treatments that are used to reduce the frequency and expected costs of wildfire and to maintain ecosystem health. We used this model to provide the first estimates, to our knowledge, of the economic efficiency of fuel treatments for rangeland systems in general, and for the Wyoming Sagebrush Steppe and Mountain Big Sagebrush ecosystems in the Great Basin in particular. We found that, on the basis of wildfire suppression costs averted, fuel treatment is economically efficient when the two ecosystems are in their healthiest ecological states, and that treatment is not efficient when the systems are in degraded ecological states dominated by invasive plants. The large economic returns to fuel treatments on healthy rangeland $(\$ 271.70$ per acre in the healthiest state in the WSS system and $\$ 357.90$ per acre in the early stages of pinyon-juniper expansion in the MBS system) reflect the fact that in both systems, the transition to degraded ecological states dominated by invasive plants would lead to permanently higher wildfire frequencies and suppression costs. These results provide quantitative support for the often-held view among rangeland managers and ecologists that the most efficient use of land management resources in systems under threat from invasive plants is to maintain ecological health and resiliency on healthy rangeland rather than to rehabilitate invaded rangeland.

Somewhat surprisingly, we found that fuel treatment is not economically efficient in degraded ecological states in either the WSS or MBS systems despite the fact that these treatments are often successful at rehabilitating degraded rangeland and preventing permanent domination by invasive annual grasses. Given the ecological benefits of treating degraded land, it is possible that our model would predict treatments on degraded rangeland are economically efficient if we were able to expand our analysis to include economic benefits of fuel treatments in addition to wildfire suppression cost savings. Relevant ecosystem goods and services affected by fuel treatment include reduced wildfire damage to public infrastructure and private property, and improvements in wildlife habitat, livestock forage, recreation opportunities, and erosion control. In order to provide a full-accounting of the benefits and costs of fuel treatments and other land management practices on rangelands, further research is needed to quantify how ecosystem goods and services other than wildfire suppression cost vary with rangeland ecological conditions.

We addressed the question of where to perform fuel treatments on an ecologically heterogeneous landscape given a fixed management budget by calculating benefit-cost ratios of treatment in different ecological states. We found that fuel treatments in the healthiest state in the WSS system have the largest benefit-cost ratio. This result suggests that treating healthy land in the WSS system is the most efficient use of public resources for fuel management. Our analysis, however, does not consider how treatment costs, treatment success rates, wildfire-return intervals, and wildfire suppression costs change over a heterogeneous landscape because of factors such as slope, aspect, wind behavior, spatial spillover effects, etc. Integrating these factors into an analysis of how to target fuel treatments would require incorporating economic information into a fully spatial landscape-scale ecological simulation model such as Shang et al. (2004). Including economic information into a more sophisticated landscape simulation model should be considered a long-run goal of the literature in economics on fuel treatments.

In addition to analyzing the economic efficiency of fuel treatments, we addressed several practical questions relevant for fuel management policy on Great Basin rangelands. In particular, we found that uncertainty about the location of thresholds between ecological states lowers the expected economic benefits of fuel treatments. This result suggests that there may be significant economic returns to research aimed at determining whether rangeland systems have crossed thresholds between ecological states. In addition, we found that in the WSS system, fuel treatment becomes economically efficient in degraded states dominated by invasive annual grasses (WSS-2, WSS-3) if either treatment success rates are substantially improved or treatment cost substantially lowered, or some combination of the two. This result implies that research that improves treatment success rates or lowers treatment costs could make treatment on degraded land dominated by invasive annual grasses economically efficient, but that these improvements would have to be dramatic relative to the baseline values considered in this article. Finally, we found that the shortening of historic wildfire-return intervals in sagebrush systems predicted by rangeland ecologists is associated with a large increase in the cost of wildfire suppression and, as a result, a large increase in the economic returns from fuel treatment. Indeed, even small decreases in wildfire-return intervals relative to the baseline values considered in this article result in fuel treatments becoming economically efficient on degraded lands.

More broadly, we presented in this article an analytical tool that incorporates the factors identified by Kline (2004) as necessary for evaluating the economic efficiency of fuel treatments. Our framework accounts for the two objectives of fuel treatment - reducing wildfire risk and restoring ecosystem health - as well as the complex relationship between invasive plants and treatment success. We captured ecological dynamics using stylized state-andtransition models from rangeland ecology. Our framework can be applied to evaluate the economic efficiency of fuel treatments in 
any ecosystems whose ecological dynamics can be described in the state-and-transition model framework. As the state-and-transition model framework is increasingly being adopted as protocol for data collection and analytical structure by U.S. government agencies such as the USDA Natural Resources Conservation Service, we expect that the simulation model presented in this article, which numerically implements state-and-transition model concepts, is going to be of increasing practical value.

In addition, our framework can be easily updated to incorporate new information on model parameters as it becomes available. This ability to incorporate new information is important because many of the parameters in the model are still subject to active research. For example, in a recent study, Balch et al. (2013) demonstrate that cheatgrass invasion has resulted in regional-scale increases in wildfire activity on rangelands in the Great Basin of the western United States, and provide estimates for wildfire-return intervals in the region based on acreage burned in wildfires from 1980-2009 that are different from the wildfire-return intervals reported in the sources cited and used in this article. ${ }^{17}$ In addition, our approach can accommodate future changes in biophysical parameters, such as wildfire-return intervals, due to climate change and other factors. The results presented in this article are, of course, contingent on parameters used in our simulation model. As such, if parameters in the model change, so will our conclusions on the economic efficiency of fuel treatments in WSS and MBS systems. Given this fact, we view the ability of our framework to incorporate new information on model parameters as it becomes available as one of the strengths of our approach.

\section{Role of funding sources}

We acknowledge support from the Nevada Agricultural Experiment Station, the Joint Fire Science Program, through SageSTEP, and the USDA Agricultural Research Service's "Area-wide Pest Management Program for Annual Grasses in the Great Basin Ecosystem". These sponsors did not play any role in the design of this study, in the manuscript preparation, or in the decision to submit this paper for publication.

\section{Acknowledgements}

We acknowledge support from the Nevada Agricultural Experiment Station, the Joint Fire Science Program, through SageSTEP, and the USDA Agricultural Research Service's "Area-wide Pest Management Program for Annual Grasses in the Great Basin Ecosystem". This is Contribution Number 69 of the Sagebrush Steppe Treatment Evaluation Project (SageSTEP), funded by the U.S. Joint Fire Science Program. We thank Krista M. Gebert from U.S. Forest Service Rocky Mountain Research Station for providing us with the wildfire suppression cost data used in this study. We thank Laine Christman and Corey Lott for their work as research

\footnotetext{
17 In particular, Balch et al. (2013) demonstrate that cheatgrass invasion has led to shorter wildfire-return intervals on Great Basin rangelands, with cheatgrass dominated land four times more likely to burn than any native vegetation type during the 1990s. Importantly, Balch et al. find that the average wildfire-return interval for cheatgrass dominated sites in the Great Basin is 78 years, which implies fire return intervals for the Great Basin as a whole that are substantially longer than the wildfire intervals for the WSS and MBS ecosystems taken from the LANDFIRE models used in this study. We rely on wildfire-return intervals reported in the LANDFIRE models because they are the only sources that we are aware of that provide wildfire-return intervals for specific ecological states in the WSS and MBS ecosystems. In contrast, Balch et al. (2013) focus on broad land cover types (i.e., cheatgrass, montane shurbland, agriculture, sagebrush steppe, pinyon-juniper, and desert shrubland) and, as such, do not report wildfire-return intervals for specific ecological states within an ecosystem.
}

assistants. The authors retain sole responsibility for the results and views presented in this paper.

\section{References}

Anderson, H.E., 1982. Aid to Determining Fuel Models for Estimating Fire Behavior. General Technical Report INT-122. USDA Forest Service, Ogden, UT.

Asefa, D.T., Oba, G., Weladji, R.B., Colman, J.E., 2003. An assessment of restoration of biodiversity in degraded high mountain grazing lands in northern Ethiopia Land Degradation \& Development 14, 25-38.

Bagchi, S., Briske, D.D., Wu, X.B., McClaran, M.P., Bestelmeyer, B.T., FernandezGimenez, M.E., 2012. Empirical assessment of state-and-transition models with a long-term vegetation record from the Sonoran Desert. Ecological Applications $22,400-411$.

Baker, W.L., 2009. Fire Ecology in Rocky Mountain Landscapes. Island Press, Washington, D.C.

Bashari, H., Smith, C., Bosch, O.J.H., 2008. Developing decision support tools for rangeland management by combining state and transition models and Bayesian belief networks. Agricultural Systems 99, 23-34.

Balch, J.K., Bradley, B.A., D’Antonio, C.M., Gomez-Dans, J., 2013. Introduced annual grass increases regional fire activity across the arid western USA (1980-2009). Global Change Biology 19, 173-183. http://dx.doi.org/10.1111/gcb.12046.

Briske, D.D., Fuhlendorf, S.D., Smeins, F.E., 2006. A unified framework for assessment and application of ecological thresholds. Rangeland Ecology \& Management 59 (3), 225-236.

Brooks, M.L., Chambers, J.C., 2011. Resistance to invasion and resilience to fire in desert shrublands of North America. Rangeland Ecology \& Management 64 (5), 431-438.

Bunting, S.C., Kingery, J.L., Hemstrom, M.A., Shroeder, M.A., Gravermier, R.A., Hann, W.J., 2002. Altered rangeland ecosystems in the interior Columbia Basin. Gen. Tech. Rep. PNW-GTR-553. Pacific Northwest Research Station. USDA Forest Service, Portland, OR.

Busenberg, G., 2004. Wildfire management in the United States: the evolution of a policy failure. Review of Policy Research 21 (2), 145-156.

Butry, D., 2009. Fighting fire with fire: estimating the efficacy of wildfire mitigation programs using propensity scores. Environmental and Ecological Statistics 16 (2), 291-319.

Calkin, D.E., Gebert, K.M., Jones, G.J., Neilson, R.P., 2005. Forest service large fire area burned and suppression expenditure trends, 1970-2002. Journal of Forestry 103 (4), 179-183.

Chartier, M.P., Rostagno, C.M., 2006. Soil erosion thresholds and alternative states in northeastern patagonian rangelands. Rangeland Ecology \& Management 59, 616-624.

Donovan, G.H., Brown, T.C., 2007. Be careful what you wish for: the legacy of Smokey Bear. Frontiers in Ecology and the Environment 5 (2), 73-79.

Egan, T.., 2009. The Big Burn: Teddy Roosevelt and the Fire that Saved America. Houghton Mifflin Harcourt.

Epanchin-Niell, R., Englin, J., Nalle, D., 2009. Investing in rangeland restoration in the Arid West, USA: countering the effects of an invasive weed on the long-term fire cycle. Journal of Environmental Management 91 (2), 370-379.

Gebert, K.M., Calkin, D.E., Huggett, R.J., Abt, K.L., 2008. Economic Analysis of Federal Wildfire Management Programs. In: Holmes, T.P., Prestemon, J.P., Abt, K.L. (Eds.) The Economics of Forest Disturbances 79. Springer, Netherlands, pp. 295-322.

Gebert, K.A., Calkin, D.E., Yoder, J., 2007. Estimating suppression expenditures for individual large wildland fires. Western Journal of Applied Forestry 22 (3), 188-196.

Government Accounting Office, 2007. Wildland Fire Management Improvements Could Enhance Federal Agencies' Efforts to Contain the Costs of Fighting Fires. Report GAO-07-922T. United States General Accounting Office, Washington, DC.

Hartsough, B.R., Abrams, S., Barbour, R.J., Drews, E.S., Mclver, J.D., Moghaddas, J.J., Schwilk, D.W., Stephens, S.L., 2008. The economics of alternative fuel reduction treatments in western United States dry forests: financial and policy implications from the National Fire and Fire Surrogate Study. Forest Policy and Economics 10 (6), 344-354.

Hesseln, H., 2000. The economics of prescribed burning: a research review. Forest Science 46 (3), 322-334.

Kline, J., 2004. Issues in Evaluating the Costs and Benefits of Fuel Treatments to Reduce Wildfire in the Nation's Forests. Research Note PNW-RN-542. USDA Forest Service, Portland, OR.

Knapp, C.N., Fernandez-Gimenez, M.E., Briske, D.D., Bestelmeyer, B.T., Ben Wu, X., 2011. An assessment of state-and-transition models: perceptions following two decades of development and implementation. Rangeland Ecology \& Management 64, 598-606.

Limbach, E., 2011. Wyoming Sagebrush Steppe. In: Fire Effects Information System. U.S. Department of Agriculture, Forest Service, Rocky Mountain Research Station, Fire Sciences Laboratory (Producer). [Online]. available from: http://www. fs.fed.us/database/feis (accessed 02.08.2011).

Loomis, J.B., 2002. Integrated Public Lands Management: Principles and Applications to National Forests, Parks, Wildlife Refuges, and BLM Lands. Columbia University Press, New York.

Loomis, J., Griffin, D., Wu, E., González-Cabán, A., 2002. Estimating the economic value of big game habitat production from prescribed fire using a time series approach. Journal of Forest Economics 8 (2), 119-129. 
Major, D.J., Sands, A.R., Tart, D., 2011. Mountain Big Sagebrush with conifers. In: Fire Effects Information System. U.S. Department of Agriculture, Forest Service, Rocky Mountain Research Station, Fire Sciences Laboratory (Producer). [Online]. Available from: http://www.fs.fed.us/database/feis (accessed 02.08.2011).

Mclver, J.D., Brunson, M., Bunting, S.C., Chambers, J.C., Devoe, N., Doescher, P., Grace, J.B., Johnson, D., Knick, S., Miller, R., Pellant, M., Pierson, F., Pyke, D., Roundy, B., Schupp, E.W., Tausch, R., Turner, D., 2010. The Sagebrush Steppe Treatment Evaluation Project (SageSTEP): A Test of State-and-Transition Theory. Vol. Gen. Tech. Rep. RMRS-GTR-237. USDA Forest Service, Fort Collins, CO.

Mercer, D.E., Prestemon, J.P., Butry, D.T., Pye, J.M., 2007. Evaluating alternative prescribed burning policies to reduce net economic damages from wildfire 89 (1), 63-77.

Millennium Ecosystem Assessment, 2005. Ecosystems and Human Well-Being Desertification Synthesis. World Resources Institute, Washington, DC.

Miller, R.F., Heyerdahl, E.K., 2008. Fine-scale variation of historical fire regimes in semi-arid shrubland and woodland: an example from California, USA. International Journal of Wildland Fire 17 (2), 245-254.

Miller, R.F., Tausch, R.J., 2001. The role of fire in pinyon and juniper woodlands: A descriptive analysis. In: Galley, K.E.M., Wilson, T.P.(Eds.), Proceedings of the Invasive Species Workshop: The Role of Fire in the Control and Spread of Invasive Species.

Miller, R.F., Svejcar, T.J., Rose, J.A., 2000. Impacts of western juniper on plant community composition and structure. Journal of Range Management 53, 574-585.

Miller, R.F., Rose, J.A., 1999. Fire history and western juniper encroachment in sagebrush steppe. Journal of Range Management 52, 550-559.

Noss, R.F., LaRoe III, E.T., Scott, J.M., 1995. Endangered Ecosystems of the United States: A Preliminary Assessment of Loss and Degradation. Biological Report 28. National Biological Service, Washington, DC.

Pellant, M., 1994. History and applications of the intermountain greenstripping program. In: Proceedings-Symposium on Ecology and Management of Annual Rangelands, 1992 May 18-22, Boise, ID. Gen. Tech. Rep. INT-GTR-313. U.S. Department of Agriculture, Forest Service, Intermountain Research Station: 63-68, Ogden, UT.

Prestemon, J.P., Abt, K.L., Barbour, R.J., 2012. Quantifying the net economic benefits of mechanical wildfire hazard treatments on timberlands of the western United States. Forest Policy and Economics 21, 44-53.

Pyne, S.J., 1982. Fire in America: a cultural history of wildland and rural fire. Princeton University Press, Princeton, NJ.

Reinhardt, E.D., Keane, R.E., Calkin, D.E., Cohen, J.D., 2008. Objectives and considerations for wildland fuel treatment in forested ecosystems of the interior western United States. Forest Ecology and Management 256 (12), 1997-2006.

Rideout, D.B., Omi, P.N., 1995. Estimating the cost of fuels treatment. Forest Science 41 (4), 664-674

Romme, W.H., Allen, C.D., Bailey, J.D., Baker, W.L., Bestelmeyer, B.T., Brown, P.M., Eisenhart, K.S., Floyd, M.L., Huffman, D.W., Jacobs, B.F., Miller, R.F. Muldavin, E.H., Swetnam, T.W., Tausch, R.J., Weisberg, P.J., 2009. Historical and modern disturbance regimes, stand structures, and landscape dynamics in pinyon juniper vegetation of the western United States. Rangeland Ecology \& Management 62 (3), 203-222.

Rummer, Bob, 2008. Assessing the cost of fuel reduction treatments: a critical review. Forest Policy and Economics 10 (6), 355-362.

Sankaran, M., Anderson, M., 2009. Management and restoration in African savannas: interactions and feedbacks. In: Hobbs, R.J., Suding, K.N. (Eds.), New Models for Ecosystem Dynamics and Restoration. Island Press, London, pp. 136-155.

Shang, B.Z., He, H.S., Crow, T.R., Shifley, S.R., 2004. Fuel load reductions and fire risk in central hardwood forests of the United States: a spatial simulation study. Ecological Modelling 180 (1), 89-102.

Sheley, R.L., James, J.J., Rinella, M.J., Blumenthal, D.M., DiTomasso, J.M., 2011. A scientific assessment of invasive plant management on anticipated conservation benefits. In: Briske, D.D. (Ed.), Conservation Benefits of Rangeland Practices: Assessment, Recommendations, and Knowledge Gaps. Allen Press, Lawrence, Kansas, pp. 291-335.

Society of Range Management, 1989. Glossary of Terms Used in Range Management, third ed. Society for Range Management, Denver, CO.

Standish, R.J., Cramer, V.A., Yates, C.J., 2009. A revised state-and-transition model for the restoration of woodlands in Western Australia. In: Hobbs, R.J., Suding, K.N. (Eds.), New Models for Ecosystem Dynamics and Restoration. Island Press, London, pp. 169-188.

Stephens, S.L., Ruth, L.W., 2005. Federal forest-fire policy in the United States. Ecological Applications 15 (2), 532-542.

Stringham, T.K., Krueger, W.C., Shaver, P.L., 2003. State and transition modeling: an ecological process approach. Journal of Range Management 56 (2), 106-113.

Stringham, T.K., Freese, E.A., 2011. State-and-Transition Models for Major Land Resource Area 24 Nevada: Final Report to USDA Natural Resources Conservation Service. USDA, Reno, NV.

U.S. Geological Survey. SAGEMAP - A GIS database for Sage-grouse and Shrubsteppe Management in the Intermountain West. http://sagemap.wr.usgs.gov/ (accessed 24.08.2011)

Westerling, A.L., Hidalgo, H.G., Cayan, D.R., Swetnam, T.W., 2006. Warming and earlier spring increase western U.S. forest wildfire activity. Science 313, 940-943.

Whisenant, S.G., 1990. Changing Fire Frequencies on Idaho's Snake River Plains: Ecological and Management Implications. INT-276, 4-10. USDA Forest Service, Ogden, UT.

Wisdom, M.J., Rowland, M.M., Wales, B.C., Hemstrom, M.A., Hann, W.J., Raphael, M.G., Holthausen, R.S., Gravenmier, R.A., Rich, T.D., 2002. Modeled effects of sagebrush-steppe restoration on Greater Sage-Grouse in the interior Columbia Basin, USA. Conservation Biology 16, 1223-1231.

Yoder, J., Gebert, K., 2012. An econometric model for ex ante prediction of wildfire suppression costs. Journal of Forest Economics 18 (1), 76-89. 